\title{
Le trésor et la bibliothèque de Patmos au commencement du $13^{\mathrm{e}}$ siècle.
}

\author{
(D'après des documents inédits.)
}

Lorsque, au mois d'avril 1088, Alexis Comnène donna Patınos à St. Christodule, nul endroit n'était plus propre à devenir, suivant l'expression du prince, «un séminaire de vertu ${ }^{1}$ ). Il faut lire la description que fait de cette solitude le commissaire impérial chargé de remettre l'île entre les mains du saint: "Ayant parcouru en tout sens l'île de Patmos, nous l'avons trouvée déserte, inculte, toute couverte d'un impénétrable fourré de broussailles et d'épines, entièrement aride par suite du manque d'eau. Par toute l'île en effet nous n'avons rencontré nulle eau courante ou jaillissante, sauf quelques petits puits, qui d'ailleurs le plus souvent ne donnent point d'eau en suffisance,.... et permettent à grand peine de mettre en culture une surface de 627 mesures: encore cette terre cultivable est-elle enfermée et comme étranglée entre de longues chaînes de montagnes. Tout le reste de l'île est un pays montagneux, rude, impraticable; dans la partie cultivable elle même, 160 mesures à peine peuvent être labourées à la charrue; tout le reste doit être travaillé à la pioche et au hoyau, et arrosé des sueurs et du sang du cultivateur; ce ne sont, pour ainsi parler, que pierres, pentes abruptes et montagnes. D'arbres nous n'avons pas vu la moindre trace, ni arbres cultivés ni même arbres sauvages, à l'exception d'une vingtaine de poiriers desséchès; semblablement nous n'avons pas aperçu une seule construction, sauf un misérable oratoire élevé, sous le vocable du vénérable Théologue, à l'intérieur de l'enceinte d'un grand temple construit au sommet de la plus haute montagne, à l'endroit où le grand apôtre a reçu les divines et mystérieuses révélations et accompli ses merveilleux miracles. ${ }^{2}$ ) A lire ce tableau peu enchanteur, on conçoit que les compagnons de St. Christodule aient

1) Miklosich et Müller. Acta et diplomata graeca medii aevi, t. VI, p. 45.

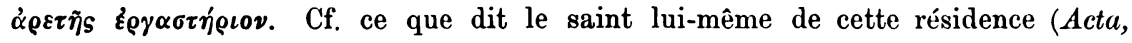

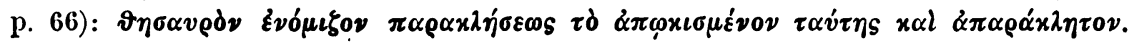

2) Acta, p. 56-57. 
regretté, sur le rocher de Patmos, les douceurs de leur couvent de Cos, et attristé par leurs plaintes, leurs récriminations, leurs défections même l'âme du saint solitaire. ${ }^{1}$ ) Ajoutez que, malgré la protection impériale, le monastère nouvellement fondé n'était pas riche, si dépourvu de ressources que la parcimonie était recommandée jusque dans l'accomplissement des œurres de charitée ${ }^{2}$; ajoutez la menace constante des descentes des corsaires $^{3}$ ), les attaques des Turcs, qui un moment chassèrent Christodule de Patmos et l'obligèrent à s'en aller mourir dans la lointaine Eubée $\left.{ }^{4}\right)$ : et l'on comprendra qu'il fallut toute la pieuse ténacité $d u$ fondateur pour soutenir l'établissement naissant, tout l'invincible attachement de ses successeurs à l'œurre du saint ascète pour la conserver intacte. Toutefois, grâce à la bienveillance impériale, qui jamais ne se relâcha, grâce aux privilèges de tout genre dont les princes de la famille des Comnènes comblèrent le couvent de Patmos ${ }^{5}$ ), les misères et les dangers du début diminuèrent avec le temps. Sans doute, jusqu'au milieu du $12^{\circ}$ siècle, le monastère connut bien des traverses, attaques des Tures, auxquels il fallut à prix d'or acheter la rançon de l'abbaye ${ }^{6}$ ), pillages des corsaires ${ }^{7}$ ), exactions des officiers impériaux, peu soucieux de respecter les privilèges $d u$ couvent ${ }^{8}$ ): malgré ces vicissitudes, le monastère prospérait. Il possédait, outre Patmos, l'île voisine de $\operatorname{Lipso}^{9}$ ), des terres à Leros ${ }^{10}$ ), des domaines en Crète ${ }^{11}$ ), et partout ses colons étaient exempts d'impôts ${ }^{12}$ ); il axait ses vaisseaux qui naviguaient en franchise par tout l'Archipel ${ }^{13}$ ); sur le montant des impôts de la province de Crète, il touchait sa bonne part en blé et en argent $\left.{ }^{14}\right)$; enfin, aux dernières années du $12^{\mathrm{e}}$ siècle, sous l'higouménat d'Arsenios, il réunissait près de cent cinquante moines. ${ }^{15}$ ) C'est à ce

1) Acta, p. 66. 88 .

2) Acta, p. 77. Cf. p. 104 et 94 .

3) Acta, p. 88 .

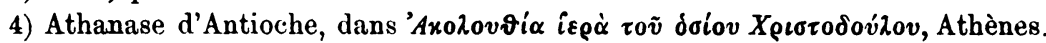
1884. p. 151. Cf. Acta, p. 85.

5) On en trouvera le résumé dans un chrysobulle de Manuel Comnène (Acta, p. 111).

6) Acta, p. 107 .

7) Acta, p. 107.

8) Acta, p. 107-108. 111-112.

9) Acta, p. 34.

10) Acta, p. 25. 34.111.

11) Acta, p. 130. 132.

12) Acta, p. 53. 94. 105.

13) Acta, p. 99. 119. 122. 127. 137. 139. 142. 151.

14) Acta, p. 99. 106-107. 117. 140.

15) Acta, p. 131. En 1157 on en compte 75 seulement (Acta, p. 108-110). Byzant. Znitschrift I 3 u. 4.

32 
moment même, où la vie matérielle mieux assurée laissait l'esprit plus libre pour des préoccupations d'autre nature, que nous reporte le curieux document, que nous publions ici pour la première fois.

Ce texte, conservé aux archives de Patmos ( $\left.\mathrm{n}^{\circ} 15\right)$, forme un long rouleau de parchemin, large de 0,26 . Au recto se trouve un inventaire fort circonstancié des icones, reliques, vases sacrés et ornements sacerdotaux, manuscrits sur parchemin et manuscrits sur papier de coton, conservés au monastère au commencement du $13^{\mathrm{e}}$ siècle; cet inventaire en effet a été dressé sous l'higouménat d'Arsenios ${ }^{1}$ ), au mois de septembre 1201. Au verso on lit une série de notes, d'une date un peu postérieure à celle du catalogue, contenant le registre des prêts faits par la bibliothèque du couvent. Déjà plusieurs fois signaléz), ce document néanmoins est jusqu'ici demeuré inédit; pourtant il est à peine besoin d'en dire toute l'importance. On sait combien sont rares ces catalogues de bibliothèques byzantines ${ }^{3}$ ), combien aussi ils sont précieux pour l'histoire des lettres au moyen-âge. Ils montrent au vif les préoccupations essentielles, les goûts dominants de l'époque où se formèrent ces collections; ils nous apprennent, quand il s'agit de librairies plus tard dispersées, la provenance de maint manuscrit aujourd'hui conservé dans les bibliothèques d'Occident ${ }^{4}$ ); peut-être sont ils plus instructifs encore, lorsque, comme à Patmos, ils concernent

1) L'higoumène Arsenios est mentionné pour la première fois dans les chartes de Patmos à la date de décembre 1188 (Acta, p. 122); la dernière mention que l'on trouve de lui se rencontre dans un acte de novembre 1199 (Acta, p. 142. Notre catalogue montre qu'en 1201 il gouvernait encore l'abbaye; mais en tout cas il était mort avant mars 1206; à cette date une charte nomme l'higoumène Euthymios (Acta, p. 150). On peut, ce semble, reconstituer ainsi, d'après les textes, la liste des premiers higoumènes du couvent:

1. Christodule 1088-1093.

2. Joseph le Jasite 1093 - vers 1128. (Acta, p. 100. 106.)

3. Sabas (?) vers 1128. ('Axoגovví, p. 154. Acta, p. 107.)

4. Theoctistos vers 1128-23 sept. 1157. (Acta, p. 107-108.)

5. Leontios 23 sept. 1157 -? (dernière mention en mai 1161. Acta, p. 117. Il quitta l'higouménat pour devenir patriarche de Jérusalem.)

6. Christodule ? - ?. (Acta, p. 144-149.)

7. Arsenios ? (1 $1^{\mathrm{e}}$ mention 1188) - ? (dernière mention en sept. 1201.)

8. Euthymios (1' mention 1206) - ?

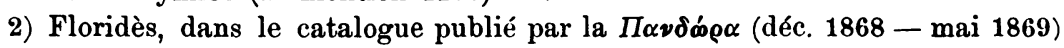

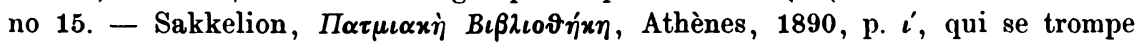
en disant que cet inventaire énumère environ 500 manuscrits. - Acta et diplomata, p. 246.

3) Krumbacher, Gesch. d. byz. Litt., p. 221-222.

4) Cf. Studemund, Das Inventar der Bibliothek des Klosters St. Johannis zu Patmos, (Philologus, 1867) p. 172-173. 
une bibliothèque moins exposée en apparence aux causes ordinaires de ruine, et qui a dû, semble-t-il, se conserver presque intacte depuis les ternps lointains de sa fondation. Or, parmi les pièces de cette sorte, inédites ou publiées ${ }^{1}$ ), qui se rapportent au couvent de Patmos, le document que nous étudions est chronologiquement le plus ancien; postérieur d'un siècle à peine à l'établissement du monastère, il nous rend à peu de choses près l'aspect primitif de la librairie; comparé aux catalogues de date ultérieure, à celui de 1355 publié par Mai ou à celui de 1382 encore inédit, il nous permet de constater les accroissements successifs réalisés au cours du $13^{\mathrm{e}}$ et du $14^{\mathrm{e}}$ siècle; enfin, rapproché d'autres documents et en particulier du catalogue de la bibliothèque actuelle ${ }^{2}$ ), il nous montre avec une cruelle précision les pertes que la collection a depuis lors éprouvées. Ainsi nous pourons en quelque manière reconstituer les fortunes diverses de la librairie de Patmos, apprendre quel fut, dans un grand couvent byzantin, le destin des manuscrits confiés à la sollicitude des moines; et si l'on songe qu'il s'agit ici d'une des plus importantes parmi les bibliothèques de l'Orient, on ne jugera point sans doute entièrement dépourvu d'intérêt cet épisode de l'histoire des livres dans les monastères grecs du moyen-âge.

L'inventaire du trésor ne mérite pas moins d'attention que le catalogue des manuscrits. On sait quelles informations précieuses fournissent les documents de cette sorte pour l'histoire des arts industriels au moyen-âge dans l'Europe occidentale et méridionale, quel parti l'on peut tirer, lorsque les monuments mêmes font défaut, de ces comptes de dépense des rois et des princes, de ces inventaires de châteaux, d'églises ou d'abbayes, conservés en si grand nombre dans les dépôts d'archives de l'Occident. ${ }^{3}$ ) «Mais, ajoute Labarte, lorsqu'il

1) Ces pièces sont, dans l'ordre chronologique: 1. Le catalogue de 1355, publié. (Migne, Patr. graec., t. 149, p. 1047.) 2. Le catalogue de 1382, inédit. (Sakkelion, loc. laud., p. ı $\alpha^{\prime}$. Acta, p. 3-4.) 3. Le catalogue du $16^{\mathrm{e}}$ siècle publié par Antoine Possevin (Catalogi mss. graec., p. 42, en appendice au t. II de l'Apparatus sacer ad script. vet. et nov. Testamenti, Cologne 1608) qui n'est qu'une traduction latine, parfois inexacte et incomplète, du catalogue de 1355. Il n'y a donc nulle importance à attacher ì l'indication qu'en donnent Montfaucon (Palaeogr. graec. p. XXI) et Sakkelion (loc. laud, p. $\iota \alpha^{\prime}$ ). Toutefois je saisis cette occasion de signaler dans le livre peu connu de Possevin plusieurs catalogues intéressants de bibliothèques constantinopolitaines $\mathrm{du} 16^{\mathrm{e}}$ siècle, $\mathrm{p}$. ex. celles du patriarchat, $\mathrm{du}$ prince Antoine Cantacuzène, etc. (loc. laud., p. 44-49). - Sur les catalogues récents de Patmos, ef. Sakkelion, loc laud., l'. $\iota \alpha^{\prime}-\iota \beta^{\prime}$.

2) Il a été dressé par Sakkelion et publié en 1390 à Athènes sous ce titre:

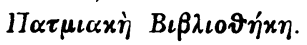

3) Labarte, Histoire des arts industriels au moyen-âge, $2^{\mathrm{e}}$ éd., t. II, p. 64-65. 
faut aborder quelque partie de l'histoire des arts industriels de l'empire d'Orient, tous ces précieux documents manquent complétement. Les manuscrits des auteurs byzantins, qui ont écrit sur la théologie ou sur l'histoire ecclésiastique et politique, ont été en grande partie conservés; plusieurs sont imprimés, traduits et commentés; quant aux documents de la vie intérieure, où se trouve la description des vases sacrés, des étoffes, des armes, des meubles et des ustensiles de tout genre à l'usage de la vie privée, ils ont presque complétement disparu. S'il en existe encore quelques uns, ils demeurent ensevelis dans les archives de quelques monastères de la Syrie ou du mont Athos, d'où peu de personnes ont encore cherché à les exhumer.» ${ }^{1}$ ) Jadis toutes les églises de Byzance possédaient de semblables inventaires de leurs richesses religieuses, et Anne Comnène, qui parle quelque part de ces documents $^{2}$ ), nous apprend qu'on les nommait des Brevia. Il y a quelques années, M. Sathas a eu la bonne fortune de retrouver un intéressant spécimen de ces monuments, l'inventaire des icones, vases sacrés et vêtements sacerdotaux donnés par Michel Attaliote au monastère qu'il fonda à Rhodosto en $1077^{3}$ ); nous sommes heureux d'y pouvoir aujourd'hui joindre l'inventaire du trésor de Patmos: il n'est pas moins curieux ni moins précieux pour l'histoire des industries d'art au moyen-âge byzantin.

I.

\section{Le trésor.}

Les richesses religieuses réunies au trésor de Patmos se partageaient en trois catégories: les reliques, les objets d'orfévrerie destinés au service du culte ou à la décoration de l'église, les étoffes précieuses et les vêtements ecclésiastiques.

On sait quelle place considérable tenait dans la vie civile et religieuse du moyen-âge le culte des reliques, et quel prix les Byzantins en particulier attachaient à ces trésors. ${ }^{4}$ ) De bonne heure la dévotion des empereurs s'était appliquée à recueillir, pour en parer les églises de Constantinople, les souvenirs matériels de la vie et des miracles du Sauveur, les ossements des saints, les monuments de leur martyre: ${ }^{5}$ ) les historiens nous racontent avec quelle ostentation on exhibait dans

1) Labarte, ibid., p. 65.

2) Anne Comnène, Alexiade (éd. de Paris) p. $156 \mathrm{~A}$.

3) Sathas, Bibliotheca graeca medii aevi, t. I, p. 47. 48-51. 68-69.

4) Riant, Des dépouilles religieuses enlevées à Constantinople, p. 3.

5) Cf. Diehl, la Pierve de Cana (Bull. de Corr. Hellén., t. IX [1885]) p. 28-32, et les textes cités par Riant, loc. laud., p. 29. 
les réceptions solennelles les merveilles vénérables entassées dans la chapelle impériale ${ }^{1}$; et la masse des reliques expédiées en Occident par les croisés de 1204 prouve surabondamment l'immensité des richesses religieuses que renfermait la capitale byzantine. ${ }^{2}$ ) Assurément le monastère de Patmos n'avait eu, au commencement du $13^{e}$ siècle, ni le temps ni les moyens d'acquérir une telle quantité de reliques; pourtant il possédait un certain nombre de monuments remarquables. $\mathrm{Au}$ premier rang figuraient plusieurs de ces fragments du bois de la Vraie Croix, auxquels les fidèles témoignaient une vénération particulière: toute église s'enorgueillissait de posséder quelqu'un de ces précieux débris, tout grand personnage tenait à honneur de suspendre à son cou quelqu'un de ces phylactères, de ces encolpia, contenant, avec d'autres reliques, une parcelle $d u$ bois de la croix. ${ }^{3}$ ) Il en allait de même à Patmos. Outre trois riches reliquaires renfermant ces insignes reliques, le trésor possédait l'encolpion d'un des premiers higoumènes, Joseph le Jasite ${ }^{4}$, où brillait un éclat $d u$ bois vénéré. Puis c'était une quantité de pieux débris, de saints ossements, entassés, un peu à l'aventure, dans des boîtes et des coffrets de toute sorte, ici dix-sept fragments grands et petits, là quarante morceaux ensemble, provenant pour la plupart de martyrs anonymes. L'inventaire ne nomme d'une façon expresse que quatre reliques: celles de St. Jacques le Perse, de St. Etienne le Jeune, de St. Hermolạos et de l'apôtre St. Philippe. On y peut joindre les restes sanctifiés de St. Paul du Latros, renfermés dans un tableau-reliquaire représentant le saint higoumène. Sans doute St. Christodule lui même avait sauvé jadis ces reliques de la destruction, au moment où l'invasion ottomane menaçait les pieuses retraites de l'Anatolie grecque ${ }^{5}$ ), et emportant avec lui les ossements de son saint prédécesseur, il leur avait assuré plus tard un asile à Patmos.

Plus intéressants que les reliquess elles-mêmes étaient les reliquaires qui les contenaient. Sans doute la plupart d'entre elles étaient placées tout simplement dans des boîtes en cuivre, en argent doré, en ivoire, dans des cassettes de bois ornées de ferrures, dans des coffrets de métal en forne de croix; toutefois les plus insignes d'entre elles avaient reçu un plus somptueux abri. L'un des morceaux de la Vraie Croix est enfermé dans une châsse d'argent doré; un autre dans un

1) Riant, loc. laud., p. 13.

2) Riant, ibid., p. 12-13. 19. 27-31.

3) Riant, loc. laud., p. 28.

4) Cf. sur ce personnage la note de la p. 501 .

5) Sur le gouvernement de Christodule à St. Paul du Latros, ef. Acta, p. 16. 17. 30. 87 . 
reliquaire du même métal, enrichi d'émaux cloisonnés ${ }^{1}$ ); un troisième est contenu dans un tableau-reliquaire, représentant les saints Georges et Démétrius, et fort semblable à plusieurs pièces conservées au trésor de Saint-Marc de Venise. ${ }^{2}$ ) A côté de ces pieux monuments, l'inventaire décrit toute une série d'autres objets d'orfêvrerie. Ce sont des images en argent doré, des diptyques, des tableaux sur bois et sur métal, représentant tantôt le Christ, la Vierge et les apôtres, tantôt quelques uns des principaux saints de l'Église grecque, St. Théodore, St. Georges, St. Démétrius, St. Nicolas et St. Jean Chrysostome, St. Cyrille et St. Athanase, St. Mercure et St. Pantéléimon, tantôt quelques scènes des saints livres, comme la Crucifixion du Seigneur ou la Dormition de la Vierge. ${ }^{3}$ ) On ne compte pas au trésor de Patmos moins de dix-neuf images de cette sorte, toutes exécutées avec le luxe habituel des orfêrres byzantins. Les unes ont des encadrements en argent doré; d'autres étincellent de pierres précieuses incrustées au front ou dans la couronne des personnages; quelques unes enfin, les plus somptueuses, sont enrichies d'émaux cloisonnés. Parmi elles brille au premier rang une grande image du patron du monastère, de St. Jean le Théologue, «avec un encadrement d'argent doré, une couronne et un Evangile ornés d'émaux cloisonnés d'or». Puis ce sont des encolpia, où l'éclat des émaux s'ajoute à la richesse de la matière; ce sont de grandes croix plaquées d'argent ou décorées de figures émaillées; c'est enfin toute la série des vases sacrés nécessaires au culte, calices, patènes, avec leurs accessoires, encensoirs et cassolettes, tous en argent ou en argent doré, et parfois ornés de figures ciselées. Sans nul doute quelques unes de ces richesses remontaient aux origines mêmes du monastère; plusieurs avaient été données peut-être par Christodule lui même à son couvent bien-aimée ${ }^{4}$ ): aussi ne saurait-on assez regretter la disparition probable $\left.{ }^{\tilde{j}}\right)$ de ces anciens et rares monuments de l'urt byzantin. A côté des pièces d'orfêvrerie, les riches étoffes de soie brodées

1) Cf. pour prendre une idée de cette pièce, le reliquaire de Limbourg (Labarte, Hist. des arts industriels au moyen-âge, $2^{\ominus}$ éd., t. I, p. 322 sq.).

2) Cf. Labarte, loc. laud., t. I, p. 318-320.

3) Sur les tableaux de cette sorte, cf. Labarte, loc. laud., t. I, p. 318-320, qui en décrit un certain nombre.

4) Dans le testament du saint, il est fait mention de plusieurs icones léguées par lui au monastère (Acta, p. 83-84). Je ne les retrouve point dans l'inventaire de 1201.

5) Il serait intéressant de rechercher dans le trésor actuel de Patmos les pièces d'orfèvrerie pouvant être identifiées avec les données du catalogue de 1201 : malheureusement je n'ai pu visiter le trésor. Il est probable d'ailleurs que la plupart des objets ont été détruits. 
ou brochées étaient un autre luxe ordinaire des églises orientales. ') Pendant de longs siècles, on le sait, la fabrication des tissus précieux demeura presque un monopole des manufactures byzantines ${ }^{2}$ ): les ateliers constantinopolitains fournissaient des produits de leur industrie le monde civilisé tout entier. Quand les empereurs voulaient faire un riche présent aux souverains de l'Occident, aux papes, aux évêques, ils leur envoyaient quelqu'une de ces somptueuses étoffes, dites impériales, brochées d'or ou historiées de figures; quand ils fondaient une église ou un monastère, ils n'étaient pas moins empressés à leur donner ces tissus admirables, «qui, dit un historien, ajoutent à la splendeur et à la magnificence des sanctuaires et témoignent de la libéralité impériale ${ }^{3}{ }^{3}$ ) On pense bien que ces merveilles de l'industrie byzantine ne manquaient point à Patmos. L'inventaire énumère des étoffes pour recouvrir les vases sacrés, des rideaux pour envelopper les reliquaires et les icones, des nappes d'autel ${ }^{4}$ ), des chasubles, des étoles, des ornements sacerdotaux de toute espèce. Tantôt ce sont des tissus de soie légère, tantôt d'épais et lourds samits ${ }^{5}$ ), aux couleurs éclatantes de pourpre et d'écarlate, aux teintes de vert de mer, de violet sombre ou de jaune citron. Certaines étoffes sont brodées, d'autres sont brochées d'or, d'autres enfin, les plus remarquables, sont décorées de sujets et de figures. ${ }^{6}$ ) Parmi ces tissus historiés, plusieurs doivent être particulièrement signalés. Ici c'est une nappe d'autel écarlate brodée de deux croix noires, ou une couverture de reliquaire ornée de figures tissées dans l'étoffe; là ce sont des vêtements sacerdotaux brodés de sujets de toute sorte; enfin ce sont trois pièces tout-à-fait intéressantes, une chasuble ancienne à figures, dite du Patriarche, et deux nappes d'autel de pourpre violette, où sur le fond éclatant de la soie se détachaient des images de griffons et d'animaux. ${ }^{7}$ ) De tous ces tissus précieux, admirables témoignages de l'industrie des artistes byzantins, pas un seul n'est parvenu jusqu'à nous: et si l'on songe que pour faire l'histoire de cet art disparu il nous reste à peine quelques lambeaux d'étoffes, si l'on remarque en

1) Müntz, la Tapisserie, p. 71.

2) Labarte, loc. laud., t. II, p. 419-4:4.

3) De Const. Porphyr., dans les continuateurs de Théophane, éd. de Bonn, p. 452.

4) Sur ces objets, cf. Labarte, loc. laud., t. III, 430.

5) Sur cette étoffe, cf. Fr. Michel, Recherches sur les étoffes de soie, d'or et d'argent pendant le moyen-âge, t. I. p. 106-119. 158-173.

6) Sur les dessins brodés ou tissés dans l'étoffe, cf. Fr. Michel. ibid., p. 14-19.

7) Une étoffe de cette sorte est décrite dans Labarte, loc. laud., t. II, 426. Eile appartient ì la cathéärale d'Aix-la-Chapelle. Une reproduction se trouve dans Labarte, t. II, p. 415. 
outre que parmi les étoffes mentionnées à l'inventaire plusieurs sont - en 1201 - désignées comme "anciennes», on ne saurait trop déplorer la perte de cette collection unique, le plus précieux peut-être de tous les trésors qu'énumère l'inventaire de Patmos.

II.

\section{La bibliothèque.}

A la différence de beaucoup d'ascètes byzantirs, chez qui la préoccupation exclusive de la foi entraine souvent quelque mépris pour la science ${ }^{1}$ ), St. Christodule parait avoir vivement senti l'importance de la culture littéraire. Dans la remarquable Instruction où il a tracé leur devoir à ses moines ${ }^{2}$ ), dans ces pages qui, malgré quelques petitesses, donnent une si haute idée de la valeur morale et du ferme bon sens de Christodule, parmi les œuvres recommandées à l'activité des solitaires, se trouve aussi l'art du calligraphe: «Si quelqu'un, dit l'Instruction, est habile en l'art d'écrire, il doit, avec l'autorisation de l'higoumène, exercer les talents dont la nature l'a doué.» ${ }^{3}$ ) Le monastère lui fournira les matières premières nécessaires, la bibliothèque s'enrichira de son cuvre, l'ecclésiarque placera son manuscrit parmi les

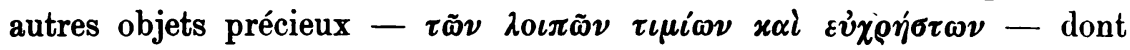
il a la garde. Le conservateur de la bibliothèque figure au reste parmi les hauts dignitaires du couvent; et il faut voir en quels termes exprès Christodule lui prescrit de veiller avec un soin jaloux ${ }^{4}$ ) sur les livres, sur les chartes contenant les privilèges de l'abbaye, sur toutes les pièces écrites qui peuvent offrir quelque intérêt pour le monastère.

Christodule joignait d'ailleurs l'exemple aux préceptes. Dans le couvent de St. Paul du Latros, qu'il gouverna pendant plusieurs années ${ }^{5}$ ), il avait une bibliothèque assez considérable; et tel était le prix qu'il attachait à cette collection, que, lorsque vers 1079 l'invasion ottomane menaça les pieuses retraites de l'Anatolie grecque, la première pensée de l'higoumène fut pour ses précieux manuscrits. En fuyant, dit une note inscrite sur un manuscrit du Latros, «il emporta avec lui tout ce qu'il put de livres $\left.»^{6}\right)$, et lui-même a raconté avec quelle sollicitude il

1) P. ex. St. Luc le Jeune (cf. Diehl, L'église et les mosaïques du cowvent de St. Luc en Phocide, p. 4).

2) Acta, p. 59-80.

3) Acta, p. 74 .

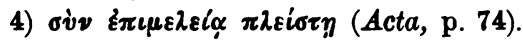

5) Acta, p. 16. 30-31. 62 .

6) Omont, Note sur un ms. grec du mont Latros. (Rev. des Etudes grecques. t. I, p. 337). 
fit, presque de force, embarquer les volumes de la bibliothèque à destination de Cos, d'où ils furent un peu plus tard transportés à Constantinople; «et si je n'avais agi de cette sorte, ajoute-t-il avec un accent de sincérité vraiment touchant, tous ces livres auraient été absolument détruits.. ${ }^{1}$ ) Plus tard, sans doute lorsqu'il fonda Patmos, Christodule demanda à l'empereur et au patriarche de lui concéder une portion de ces manuscrits du Latros que son énergie avait sauvés; il obtint en effet le quart de la collection, et quoique sa part ne comprit que les moins beaux d'entre ces volumes, il s'en montra vivement satisfait. $\left.{ }^{y}\right) \Pi$ augmenta bien vite, à force de recherches et de dépenses, ce premier noyau de bibliothèque ${ }^{3}$ ), et jusqu'à la fin il garda pour ces volumes si laborieusement rassemblés un attachement passionné. Quand, au déclin de sa vie, il dut une nouvelle fois s'enfuir devant l'approche des Turcs, de nouveau il emporta avec lui dans la lointaine Eubée ses chers manuscrits; et durant ses derniers jours, alors qu'il s'occupait tout entier à assurer l'avenir de son couvent bien aimé, ses livres demeurèrent l'une de ses principales pensées. En mourant, il voulut tous les léguer à l'abbaye, «afin qu'ils demeurassent éternellement dans ce monastère de Patmos ${ }^{4}$ ), et nulle précaution ne lui sembla superflue pour en garantir la conservation. Il fait dresser le catalogue de ces précieux volumes, et le remet, signé de sa main, à l'un de ses disciples, afin que nul manuscrit ne puisse être détournéb); il ordonne que tout soit exactement remis aux mains du nouvel higoumène, et appuie ses injonctions de la menace de la damnation éternelle ${ }^{6}$ ); il recommande à son fidèle Sabas de veiller au retour de la bibliothèque à Patmos ${ }^{7}$ ); il interdit aux abbés ses successeurs d'aliéner jamais aucune pièce de la collection; il leur enjoint de repousser sans merci toutes les réclamations venant des couvents du Latros, toutes les protestations élevées contre la douation légitimement faite à Christodule par le patriurche: «Si jamais quelqu'un tentait, au nom du monastère de Stylos ou de quelque autre abbaye du Latros, de revendiquer quelqu'un des livres qui m'ont été donnés par le très saint patriarche, qu'il soit débouté de sa demande et qu'il attire sur lui la malédiction des trois cents dix huit pères et la mienne.» ${ }^{8}$ )
1) Acta, p. 87 .
2) Acta, p. 87
3) Acta, p. 87 .
4) Acta, p. 83 .
5) Acta, p. 83 .
6) Acta, p. 86-87.

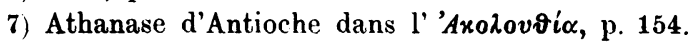
8) Acta, p. 87 . 
Les successeurs de St. Christodule ne furent pas moins empressés que lui à enrichir la bibliothèque de Patmos. Les uns, tels que Joseph le Jasite, réunissent de riches manuscrits, qu'ils lèguent en mourant au monastère ${ }^{1}$ ); d'autres, tels que l'higoumène Arsénios, ne dédaignent point de copier quelques volumes de leur main ${ }^{2}$ ), et les moines imitent cet exemple. ${ }^{3}$ ) D'autre part, au cours du $12^{\mathrm{e}}$ siècle, les dons de livres affluent à l'abbaye; il en vient de Rhodes, de Chios, de la Crète, d'ailleurs encore; les donateurs, comme l'attestent les souscriptions de quelques manuscrits actuellement conservés à Patmos, croient par ces cadeaux faire œurre pie et assurer leur salut éternel ${ }^{4}$ ), et ils n'épargnent rien pour que le présent soit beau et digne de l'abbaye. L'un d'eux, dans la souscription qui accompagne le livre, énumère, non sans emphase, les sommes qu'il a dépensées pour l'achat du papier, pour la copie, pour la reliure, pour la notation musicale.") Un autre, un humble moine de Rhodes, offre avec une modestie touchante le manuscrit copié de sa main, et la souscription nous montre en même temps quelle activité littéraire animait le couvent vers le milieu du $12^{\mathrm{c}}$ siècle: «J'ai consacré, dit le donateur, dans le vénérable et saint monastère de Patmos le présent livre, non point que le couvent n'en possède point de semblable; loin de moi une telle pensée! quel monastère en effet renferme plus de savants hommes et de pieux calligraphes que la divine abbaye du Théologue?» ${ }^{6}$ ) Aujourd'hui encore on conserve à Patmos toute une série de volumes datés de ce temps ${ }^{7}$ ); sans doute plusieurs d'entre eux ont été écrits de la main même des saints solitaires.

On conçoit que de cette sorte une librairie assez importante ait pu exister à Patmos en l'année 1201. Le catalogue énumère 267 manuscrits sur parchemin ${ }^{\S}$ ), 63 sur papier de coton, en tout 330 volumes. Toutefois, il faut le dire sans tarder, la composition de cette bibliothèque ne répond point, du moins à nos yeux, aux espérances qu'éveille d'abord le nombre de ses livres. Les manuscrits liturgiques, les œuvres des Pères

1) Catalogue de 1201, passim.

2) Ibid.

3) Ibid.

4) Sakkelion, loc. laud., p. 95-96. 119.

5) Ibid., p. 119.

6) Sakkelion, loc. laud., p. 95.

7) Ibid., no 9 de 1192 , no 120 de 1194 , no 175 de 1174, no 218 de 1167, no 221 entre 1143 et 1179 , no 262 de 1192.

8) Pourtant on observera que sur ces 267 mss., 7 numéros ont été ajoutés d'une autre main à la fin du chapitre des membranacei, et 2 également d'une autre main, à la fin du chapitre des bombycins. Mais en tout cas ces additions ne sauraient être de date bien postérieure à la rédaction du catalogue. 
de l'Eglise y tiennent une place prépondérante; les auteurs classiques y manquent presque absolument. Sur 267 manuscrits sur parchemin, il n' y a pas moins de 109 livres liturgiques, Evangiles, Psautiers, Octoïchos, Triodion, Euchologes, Panégyriques, Synaxaires, Ménées et Kontakia. Les Vies de saints de Syméon Métaphraste forment 23 numéros, et cette série hagiographique se grossit encore de quelques œurres de même nature, Vies de St. Pachôme, de St. Théodore d'Edesse ou de St. Théodore Studite, Histoire Lausiaque ou «Paradis». Les manuscrits des Pères ne sont guère moins abondants: on en compte 26 de St. Jean Chrysostome, 13 de St. Basile, 6 de Grégoire de Nazianze, 5 de Grégoire de Nysse, sans nommer les volumes de Mélanges tirés des Pères, et les nombreux commentaires des Livres saints empruntés à leurs ouvrages. Puis, c'est la Philocalie d'Origène, l'histoire ecclésiastique et les commentaires sur l'Ecriture de Théodoret de Cyr, des traités de St.-Athanase ou de St. Ephrem, les dialogues de Grégoire le Grand traduits en grec. Enfin la patristique proprement byzantine n'est pas moins bien représentée. Patmos possède les ouvrages de St. Jean Damascène et de St. Théodore Studite, les traités de Jean Climaque et de St. Maxime le confesseur; on y trouve le livre d'Antiochus moine de St. Sabas, les lettres de Michel le Diacre, les commentaires de Léon le Philosophe, les écrits de l'évêque Basile de Néopatras; on y rencontre même des cuvres de date assez récente, comme la Panoplie dogmatique d'Euthymios Zigabenos, ou le livre de Syméon, moine de St. Mamas, que l'on surnommait le second Théologue. En face de cet amas de littérature religieuse, à grand peine découvre-t-on une douzaine de volumes ayant l'aspect profane: encore la plupart d'entre eux semblent de bien mince importance. Ce sont deux volumes sur la grammaire $(\Gamma \varrho \alpha \mu \mu \alpha$ -

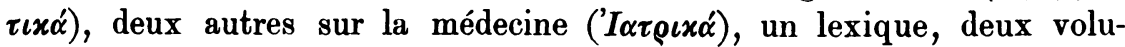

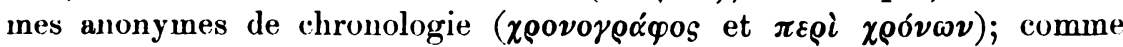
ouvrages de valeur, je ne trouve à citer, après deux exemplaires du célèbre roman de Barlaam et Joasaph, qu'un volume de Josèphe, un commentaire d'Eustathe sur les Antiquités judaüques du même auteur, et un manuscrit contenant en tête les Catégories d'Aristote.

$\mathrm{Si}$ nous passons aux manuscrits bombycins, nous n'aurons guère qu'à répéter les observations précédentes. Sur 63 volumes énumérés, il $\mathbf{y}$ a près d'une vingtaine de livres liturgiques; puis ce sont des vies de saints ascètes, tels que St. Syméon, St. Cassien ou St. Barsanuphios, et de saints plus modernes, comme Théophane et Théodore Graptos; c'est une vingtaine de manuscrits des Pères, où l'on trouve, à côté des grandis noms de la patristique, des écrits de St. Epiphane, des homélies d'André de Crète, des lettres d'Isidore de Péluse et les commentaires 
sur les Evangiles de l'archevêque Théophylacte de Bulgarie. Cinq ou six manuscrits seulement représentent la part de la littérature profane: c'est un lexique, un manuscrit d'Aristote, sans autre indication que le nom du philosophe, et trois ouvrages historiques, dont deux méritent d'être particulièrement signalés, tant est rare dans les bibliothèques monastiques de l'Orient la rencontre de volumes de cette sorte: c'est la chronographie du patriarche Nicéphore et l'histoire de Scylitzès. ${ }^{1}$ )

On voit quelle place exclusive est faite dans la librairie de Patmos aux livres liturgiques, aux cuvres d'hagiographie, de patristique et d'édification: sur 330 manuscrits, il n'y a pas vingt volumes touchant de près ou de loin à la littérature profane; et ce seul fait éclaire d'une lumière significative les préférences intellectuelles des moines byzantins du $12^{\circ}$ siècle. Toutefois dans cette vaste collection d'ouvrages sacrés,

1) Il m'a paru utile de résumer dans les tableaux suivants les données que fournit le catalogue de 1201 sur la composition de la bibliothèque de Patmos.

I. Manuscrits sur parchemin.

Evangéliaires

Apôtres

Psautier

Octoïchos, Canons

Triodion

Ménées

Panégyriques

Euchologe

Kontakia

Sticheraria

Synaxaires

Autres livres liturgiques

Nomocanon

Métaphrases

Uuvrages de l'ancien Testament

(Job, Proverbes, Ecclésiaste)

\section{Apocalypse}

4 Commentaires des livres saints 8

6 St. Basile 13

18 St. Chrysostome 26

3 St. Grégoire de Nazianze 6

25 St. Grégoire de Nysse 5

9 St. Jean Damascène 2

6 St. Théodore Studite 3

10 Theodoret de $\mathrm{Cyr}$

6 Autres œuvres de patristique (Gré-

2 goire le Grand, Origène, etc.) 25

8 Mélanges tirés des pères . 4

3 Vies de saints 8

23 Ouvrages profanes 12

Divers

144
St. Marc
Psautier
Octoïchos
Ménées
Synaxaires
Autres livres liturgiques
Livres de l'ancien Testament (Rois,
$\quad$ Job)

Commentaires des livres saints St. Basile

II. Manuscrits bombycins.

1 St. Chrysostome 1

3 St. Grégoire de Nazianze 1

+ St. Grégoire de Nysse 2

2 Théodoret 1

3 Autres œurres de patristique (St.

5 Hippolyte, Climaque, etc.) 14

Vies de saints 5

4 Ouvrages profanes 5

$\begin{array}{lll}2 & \text { Divers } & 7 \\ 3 & & 63\end{array}$ 
il y a autre chose qu'un simple fatras liturgique ou théologique. Certains ouvrages mentionnés au catalogue ont la valeur de véritables monuments historiques: c'est ainsi qu'on conservait pieusement l'Euchologe de St. Christodule, qui portait sur sa reliure l'image en argent du saint higoumène. ${ }^{1}$ ) D'autres manuscrits non moins précieux avaient appartenu à l'un des premiers successeurs de Christodule, à l'higoumène Joseph le Jasite, dont les textes vantent la vertu, les bonnes œurres, la sollicitude pour le monastère ${ }^{2}$ ), et qui, à l'exemple de son illustre prédécesseur, avait en mourant laissé plusieurs volumes au couvent. ${ }^{3}$ ) Un Euchologe richement relié venait de Constantin, évêque de Leros, celui-là même qui en 1157 assista à ses derniers moments l'higoumène Theoctistos. ${ }^{4}$ ) D'autres manuscrits se recommandaient à l'attention par leur valeur artistique, par les riches reliures dont ils étaient habillés. En tête du catalogue sont énumérés quatorze volumes, principalement des Evangéliaires, dont les couvertures étaient décorées d'ornements et de figures en argent ou en argent doré. On y voyait les sujets habituels à l'orfèvrerie religieuse byzantine, la Crucifixion, les quatre Evangélistes, la Theotokos, le Théologue, l'image du Christ ou celle de la Croix, sans qu'on puisse d'ailleurs déterminer avec exactitude si ces compositions étaient exécutées en bas-reliefs ou si des émaux venaient ajouter à la richesse de la matière le charme de la couleur. Enfin, même en faisant abstraction de ces précieux volumes, on doit reconnaître que la bibliothèque de Patmos était composée d'une manière assez heureuse et convenable au grand établissement monastique auquel elle était destinée. Non seulement elle renfermait la plupart des œurres importantes de la littérature religieuse; elle possédait en outre de nombreux écrits hagiographiques, et quantité de traités d'écrivains de second ordre, dont plusieurs nous sont assez mal connus. Flle contenait certains manuscrits de luxe, tels que ce St. Basile ou ce St. Grégoire de Nazianze que le catalogue désigne de

1) Catalogue de 1201.

2) Acta, p. 106-107.

3) Joseph le Jasite est mentionné dans deux documents, dans un chrysobulle non daté de l'empereur Jean Comnène $(1118-1143)$ et dans le testament de l'abbé Theoctistos (1157). On voit qu'il était higoumène de Patmos et qu'il fut dans le gouvernement du monastère le prédécesseur immédiat de Theoctistos (Acta, 107): or, celui-ci ayant administré le couvent pendant près de trente ans (Acta, 107) et étant mort en 1157, on doit placer son avènement et la mort de Joseph le Jasite vers l'an 1128. Il semble bien d'autre part qu'il ait été le premier successeur de St. Christodule (Acta, 100); en tout cas il parvint à l'higouménat sous le règne d'Alexis Comnène (Acta, 100. 106).

4) Actu, p. 108. 113 . 
l'épithète $\mu \varepsilon \varepsilon^{\prime} \alpha$; elle avait un assez grand nombre de manuscrits anciens; à chaque page du catalogue revient l'épithète de $\pi \alpha \lambda \alpha \iota \delta$ ou de $\pi \alpha \nu v$ $\pi \alpha \lambda \alpha \iota \nu^{\nu}$; et quand ce terme s'applique à des manuscrits bombycins, il prend - tant sont rares les manuscrits sur papier antérieurs au $13^{\mathrm{e}}$ siècle $\left.^{1}\right)$ - une valeur et un intérêt tout particuliers.

On se demandera tout naturellement ce que sont devenues tant de richesses, et si la bibliothèque de Patmos les a conservées dans leur intégrité. Il faut, pour s'en rendre compte, comparer l'inventaire de 1201 avec le catalogue actuel dressé par les soins de Sakkelion: le rapprochement est, on va le voir, singulièrement instructif et attristant.

Il est incontestable tout d'abord que, des manuscrits sur parchemin inscrits au catalogue de 1201, un assez grand nombre figure encore sur les rayons de la bibliothèque. Pour beaucoup d'entre eux, l'identification peut être faite d'une façon certaine, pour plusieurs avec des chances de très grande vraisemblance. ${ }^{2}$ ) On voit par là que dès la fin du $12^{\mathrm{e}}$ siècle Patmos possédait la plupart des beaux manuscrits calligraphiques qu'il renferme aujourd'hui, par exemple le Job commenté, qui date de la fin du $7^{\mathrm{e}}$ ou du commencement du $8^{\mathrm{e}}$ siècle (Sakkelion, no 171) et l'admirable Grégoire de Nazianze écrit en 941 à Reggio de Calabre (no 33). D'une manière générale, la plupart des manuscrits de date un peu ancienne actuellement conservés au couvent semblent avoir dès cette époque fait partie de la librairie; on retrouve dans l'inventaire de 1201 et le St. Jean Chrysostome de 988 (no 138), et le Commentaire sur les Evangiles de Titus, évêque de Bostra (no 59), qui date du $9^{e}$ ou $10^{e}$ siècle, et le St. Basile de 1082 (no 20) et le St. Maxime de la même année (no 192) et la Philocalie d'Origène transcrite au $10^{\circ}$ siècle (no 270) et la plupart des manuscrits copiés aux $9^{\circ}, 10^{\circ}$ et $11^{\mathrm{e}}$ siècles: et la chose s'explique aisément, ces manuscrits anciens ayant presque tous dû appartenir à la bibliothèque primitive formée par St. Christodule. On peut de même identifier un certain nombre de manuscrits de la fin du $12^{\circ}$ siècle, qui venaient d'entrer à la bibliothèque au moment où fut dressé l'inventaire: on reconnaît de cette sorte et la Vie de St. Pachôme de 1192 (no 9) et le roman de Barlaam de 1194 (no 120) et les Canons de la Vierge offerts en 1174 par le moine Nil de Rhodes (no 175) et le Synaxaire de 1192 (no 262) et les Sticheraria datés de 1167 (no 218. 221). On retrouve non moins aisément toute la longue série des Vies de Saints du Métaphraste, où, sur 28 volumes présentement conservés au couvent, 17 déjà figurent

1) Cf. Gardthausen, Griech. Palaeogr., p. 50.

2) On trouvera, dans les notes qui accompagnent le texte du catalogue de 1201, l'indication très précise de ces identifications. 
au catalogue de 1201. Enfin, si l'on cherche à identifier les riches Evangéliaires énumérés dans l'inventaire, on peut, semble-t-il, les retrouver avec de grandes chances de probabilité. Actuellement Patmos ne possède pas moins de vingt-quatre manuscrits de cette sorte antérieurs au $13^{\mathrm{e}}$ siècle; beaucoup d'entre eux sont accompagnés de la notation musicale, plusieurs sont enrichis de miniatures, trois d'entre eux (no 74. 84. 274) sont couverts de reliures de prix, et sans doute la plupart de ces beaux volumes, évidemment destinés à la celébration des offices religieux, en étaient originairement revêtus. On peut donc admettre avec grande vraisemblance que les Evangéliaires de 1201 se trouvent pour la plupart parmi ces manuscrits; pour deux d'entre eux l'identification est même certaine; les couvertures des no 74 et 274 correspondent exactement à deux des reliures décrites dans l'inventaire. Mais à l'exception de ces deux pièces, d'ailleurs fort remarquables ${ }^{1}$ ), Patmos n'a gardé nulle trace des précieux monuments d'orferrerie qui enrichissaient ses manuscrits à la fin du $12^{e}$ siècle; et si l'on remarque par surcroît que, parmi les rares couvertures d'Evangéliaires conservées, plusieurs sont en fort mauvais état ${ }^{2}$ ), la disparition totale des autres excitera les plus légitimes inquiétudes sur le soin qu'ont apporté les moines de Patmos à garder les richesses de leur librairie.

Et en effet, sur 267 manuscrits sur parchemin mentionnés en 1201, à grand peine peut-on en retrouver 108 dans le catalogue actuel. ${ }^{3}$ ) Plus de la moitié des lirres possédés par le couvent au commencement du $12^{\circ}$ siècle sont aujourd'hui irrémédiablement perdus, et parmi eux, presque tous ceux que l'inventaire désignait comme particulièrement anciens. Perdus, ces vingt-cinq volumes de Ménées, dont plusieurs se

1) L'une (no 74) représente la Crucifixion; d'un côté de la croix se tient la Theotokos, de l'autre St. Jean; aux angles sont les figures des quatre Evangèlistes. L'autre ais est orné de clous en forme d'étoile. La reliure du no 274 représente la Crucifixion au centre, les quatre Evangélistes aux angles. Toutes ces figures sont exécutés en bas reliefs d'argent, sans nulle adjonction d'émaux.

2) Le no 84 , du $11^{\mathrm{e}}$ siècle, mais qu'on ne peut identifier à aucune des couvertures de 1201, est fort endommagé. Le no 81 (de 1345) n'a plus qu'un de ses ais. Le no 75 (de 1460) est plus maltraité encore. De même le no 274 paraît avoir perdu un de ses ais.

3) Il faut toutefois tenir compte de la considération suivante: beaucoup de manuscrits mentionnés à l'inventaire sont de minces plaquettes $\left(\beta \iota \beta \lambda_{\iota} \delta \alpha \dot{\rho} \iota \alpha, \beta \iota \beta \lambda_{\iota-}\right.$

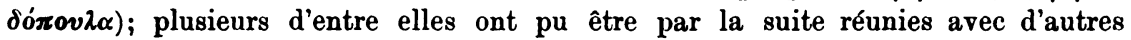
brochures sous une reliure commune, et parvenir jusqu'à nous, perdues en quelque sorte dans un volume plus compact. Ainsi le no 112 renferme la lettre de St. Athanase au duc Antiochus, le no $\mathbf{1 7 9}$ contient la Vie de Constantin. Cependant ces cas ne sont pas bien nombreux et diminuent de quelques unités à peine le total des manuscrits perdus. 
recommandaient par leur antiquité; perdus, ces précieux Euchologes, parmi lesquels on remarquait celui de St. Christodule; perdus, ces Kontakia vénérables, qui contenaient la liturgie de St. Basile, ou de St. Chrysostome; perdues, ces 'Axodovvial de St. Marine, de St. Thomas, des Saints Archanges. Sur les vingt-six volumes de Chrysostome, quatorze ont disparu, et parmi eux l" $E \xi \alpha \eta \mu \varepsilon \rho o s$, qui figure encore au catalogue

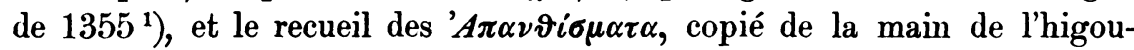
mène Arsenios; sur les treize manuscrits de St. Basile, huit sont perdus; des cinq manuscrits de Grégoire de Nysse, pas un seul n'est conservé. De ces écrivains de second rang, si nombreux au catalogue de 1201, rien ou presque rien ne reste: perdus, le livre d'Antiochus de St. Sabas, les écrits de Sophronius de Damas et les traités de l'abbé Esaïe le solitaire; perdues, les lettres de St. Dorothée, les homélies de Jean le Géomètre, les cuvres d'Isaac le Syrien; perdus, le livre de Syméon de St. Mamas et le recueil appelé la Melissa ou St. Nicon. L'histoire ecclésiastique de Théodoret de Cyr, les lettres du moine Michel figurent encore au catalogue de $1355^{2}$ ); aujourd'hui elles ont disparu. Il en est de

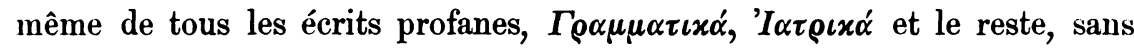
excepter Josèphe, ni le commentaire d'Eustathe, ni les Catégories d'Aristote. Veut-on par quelques chiffres préciser l'étendue du désastre? Aujourd'hui, sur 305 manuscrits sur parchemin conservés au couvent de Patmos, 208 sont antérieurs au commencement du $13^{\circ}$ siècle, et sur ces 208 volumes, beaucoup, on en a la preuve ${ }^{3}$ ), sont entrés dans la bibliothèque postérieurement à l'année 1201 . Or à cette date, le monastère possédait un nombre de volumes sur parchemin - 267 - notablement supérieur au chiffre des manuscrits anciens qu'il conserve aujourd'hui. On peut donc admettre sans exagération qu'une moitié au moins des manuscrits sur parchemin mentionnés au catalogue de 1201 sont actuellement perdus sans retour. Pour les bombycins, le désastre est plus complet encore. En 1201, Patmos en comptait 63; aujourd'hui, sur les 429 manuscrits sur papier que garde le monastère, six seulement sont antérieurs au $13^{\mathrm{e}}$ siècle; parmi eux, trois à peine peuvent être identifiés avec des volumes de 1201 ; le reste - soixante volumes - a irrémédiablement disparu.

Sans doute il faut reconnaitre que beaucoup des pertes faites ne sont point irréparables. La plupart des ourrages inscrits au catalogue de 1201 nous sont amplement connus par d'autres manuscrits; certains d'entre eux sont, à Patmos même, représentés par des copies de date

1) Migne, Patr. graec., t. 149, p. 1047, no 38.

2) Migne, loc. laud., no 50 et 27.

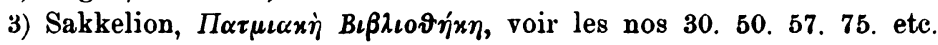


postérieure. ${ }^{1}$ ) Cependant quelques documents uniques et curieux ont sans doute sombré dans le naufrage; et lors même qu'il s'agit de textes déjà connus d'autre part, la perte d'exemplaires très anciens n'est pas moins attristante. Pour l'histoire de la paléographie, la disparition des bombycins est tout particulièrement déplorable: il reste si peu de manuscrits sur papier de date antérieure au $13^{\circ}$ siècle, on est si mal informé de l'époque où le papier de coton entra d'abord en usage, qu'on ne saurait assez regretter la ruine de soixante manuscrits de cette sorte, dont plusieurs sont, à tort ou à raison, désignés au catalogue de 1201 comme étant «très anciens».

Il faut en terminant essayer de rendre compte des causes qui ont privé la bibliothèque de Patmos de près de deux cents manuscrits antérieurs au $13^{\mathrm{e}}$ siècle. La principale est sans nul doute la négligence apportée par les moines dans l'entretien de leurs manuscrits. Les preuves se présentent ici avec une abondance tout-à-fait regrettable. Si l'on examine par exemple le catalogue de 13555 , qui se borne à enregistrer les manuscrits les plus importants de la librairie, on constate que plusieurs de ces précieux volumes sont désignés comme étant «fort endommagés $\left.\gg^{2}\right)$ : à ce titre, ils méritaient, ce semble, une sollicitude toute particulière; au contraire on en a pris si peu de soin qu'ils ont aujourd'hui disparu. Veut-on savoir ce que sont devenus maints volumes nommés dans l'inventaire de 1201? qu'on regarde les reliures de la bibliothèque actuelle: on y trouvera par exemple des feuillets du livre d'Antiochus de S. Sabas ${ }^{3}$ ), des fragments d'histoire ecclésiastique ${ }^{4}$ ), des lambeaux d'Evangéliaire $^{5}$ ), des morceaux de Dion Chrysostome $^{6}$ ), qui attestent surabondamment le cas qu'on a fait des manuscrits originaux. Parcourez enfin quelques uns des volumes que l'on conserve présentement à Patmos, par exemple le no 272 ou le no $420^{7}$ ): ils se composent de fragments de toute sorte, appartenant à des mauuscrits fort différents, qu'une main prévoyante a, malheureusement bien tard, réunis sous une reliure commune. Dans le no 272 en particulier on rencontre des fragments de St. Jean Chrysostome, des homélies de Grégoire de Nazianze, de

1) C'est le cas pour Syméon de St. Mamas (no 390 et 427), pour Isaac le Syrien (no 362), pour l'Evergetikon du moine Paul (no 441. 442), pour d'autres encore.

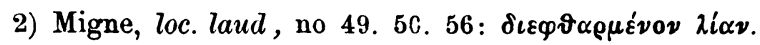

3) Duchesne et Bayet, Mission au Mont Athos (Archives des Missions,

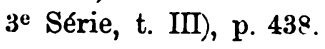
4) Ibid., 437.
5) Ibid., 438.
6) Ibid., 439 .
7) Sakkelion, p. 140 et 187.

Byzant. Zeitschrift I 3 u. 4. 
St. Basile, de St. Ephrem, de St. Athanase, des morceaux de Vies de saints, d'autres pièces encore, provenant d'une série de manuscrits du $10^{\mathrm{e}}$ et du $11^{\mathrm{e}}$ siècle. Sans nul doute ces volumes appartenaient à la bibliothèque primitive; lacérés plus tárd et mis en pièces, ils n'ont laissé subsister que l'ombre d'eux-mêmes; et je ne parle même pas des manuscrits, fort nombreux à Patmos, où l'on constate, au début ou à la fin du livre, l'absence d'un certain nombre de feuillets. Tout cela atteste, on l'avouera, une incurie navrante. D'autres circonstances encore ont pu contribuer au désastre. La librairie de Patmos, on le verra, prêtait assez libéralement ses manuscrits au $13^{\circ}$ siècle; près d'une cinquantaine de volumes sont sortis de cette manière, et dispersés, les uns à Leros, à Calymnos, à Cos, à Samos, d'autres sur la côte d'Anatolie, à Palatia ou dans les couvents du Latros, d'autres plus loin encore, et jusqu'en Crète. Les livres ainsi échappés à la garde de l'ecclésiarque ont-ils toujours fait scrupuleusement retour à la bibliothèque? les désastres imprévus qui si souvent, en ces siècles troublés, sont venus s'abattre sur les côtes ou les îles de l'Archipel, n'ont-ils pas pu détruire quelques uns de ces manuscrits? La chose est plus que rraisemblable. Il n'en demeure pas moins acquis que la librairie de Patmos, si importante à la fin du $12^{\text {e }}$ siècle, a peu à peu laissé perdre beaucoup de ses plus précieuses richesses, et il $\mathrm{y}$ a quelque intérêt peut-être à examiner en quel temps sa décadence a commencé.

Si l'on étudie les documents du $13^{\text {e }}$ et du $14^{\circ}$ siècle relatifs à la librairie de Patmos, il semble que, loin de décroître, la bibliothèque ait d'abord prospéré. Malgré les dangers auxquels le monastère fut exposé au cours du $13^{e}$ siècle, malgré les constantes attaques des pirates dont les insultes et les flèches montaient jusqu'aux portes closes de l'abbaye, malgré les ravages des Vénitiens, qui rançonnaient sans merci les îles de l'Archipel et obligeaient l'higoumène Germanos à vider le trésor du couvent pour sauver sa communauté du massacre ${ }^{1}$ ), malgré les amertumes de tout genre, auxquelles le monastère dut se résigner, la librairie ne cessait de s'enrichir. Vers la fin du $13^{\text {e }}$ siècle, l'abbé Sabas lui laissait par testament une trentaine au moins de manuscrits ${ }^{2}$ ), parmi lesquels il faut noter, à côté de livres de liturgie, d'hagiographie et de patristique, une série de lettres des patriarches de Constantinople, deux volumes d'histoire ecclésiastique, et un ouvrage juridique, le חøó-

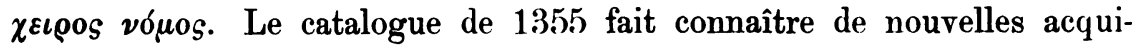
sitions. Sans doute ce document ne nous fournit qu'une liste sommaire

1) Acta, p. 230 .

2) Actı, p. 241-243. 
des manuscrits principaux de la librairie: il n'en est pas moins singulièrement instructif. Sur 58 numéros qu'il comprend, 22 au moins, - plus du tiers - ne figurent point à l'inventaire de 1201 et sont entrés à la bibliothèque postérieurement à cette date. Parmi eux, on retrouve deux des volumes de l'higoumène Sabas, le traité du pseudo-Denys l'Aréopagite $^{1}$ ) et l'histoire ecclésiastique d'Evagrius ${ }^{2}$ ); les vingt autres, quelle qu'en soit l'origine, sont plus intéressants encore. A côté des manuscrits des Pères, tels qu'Anastase, Grégoire de Nysse ou Nemesius d'Emèse $^{3}$ ), des commentaires de Nicétas de Serres ou de Macarius de Philadelphie ${ }^{4}$ ), à côté des pieuses élucubrations dues au zèle religieux de certains empereurs, tels qu'Isaac Comnène ou Mathieu Cantacuzène ${ }^{5}$ ), apparaissent des œurres historiques ou philosophiques et des manuscrits d'auteurs classiques. Ce sont les écrits de Nicéphore Chumnos, faussement mis sous le nom de Scylitzès ${ }^{6}$ ); c'est une partie de la chronique de Zonaras et une histoire des Paléologues d'un certain Georges ${ }^{7}$ ); c'est un exemplaire des Basiliques ${ }^{8}$ ); ce sont enfin trois manuscrits de Diodore de Sicile, de la Cyropédie de Xénophon et des dialogues de Platon. ${ }^{9}$ ) A ce moment un esprit nouveau semble animer vraiment le couvent de Patmos; l'antique sévérité se relâche, qui jadis rendait les moines si hostiles aux ouvrages profanes; leur curiosité s'étend au-delà des étroites limites de l'hagiographie et de la patristique, et les livres d'histoire en particulier trouvent à l'abbaye une faveur aussi remarquable que rare dans les monastères byzantins. ${ }^{10}$ )

1) Migne, loc. laud., no 41.

2) Migne, ibid., no 49.

3) Migne, ibid., no 33. 23. 35. 30.

4) Migne, ibid., no 36. 37, 16. Dans la même série d'acquisitions nouvelles figurent les numéros suivants du catalogue de 1355: no 2. 31. 57. 7 bis. Nous désignons ainsi un volume mentionné dans la traduction latine publiee par Possevin. Après le commentaire de Job (no 7 de Migne) on lit: In Esaiam expositio Basilii, Chrysostomi, Theodoreti et aliorum, manuscrit qui manque dans le texte grec de la Patrologie. Le volume suivant (no 8 de Migne), décrit par Possevin sous le titre: In eumdem Basilii solius expositio, n'est donc point le commentaire de St. Basile sur Job, mais bien le commentaire de ce père sur Esaie. Les deux volumes se retrouvent dans la bibliothèque actuelle (Sakkelion, no 214 et 26): le second figure déjà au catalogue de 1201.

5) Migne, ibid., no 32, 9.

6) Migne. ibid., no 29.

7) Migne, ibid, no 58. 46.

8) Migne, ibid., no 45.

9) Migne, ibid., no 47. 54. 55.

10) Cf. sur ce point Krumbacher, Gesch. d. byz. Liti., p. 220. Aujourd'hui encore Patmos possède un manuscrit de la chronique de Georges le moine (Sakkelion, no 7). 
Malheureusement ce beau zèle ne paraît point avoir dépassé la seconde moitié du $14^{\mathrm{c}}$ siècle. On a vu que dès 1355 certains manuscrits étaient fort endommagés; d'autres, qui de 1201 à 1355 s'étaient conservés intacts ${ }^{1}$ ), disparaissent après cette date et sont aujourd'hui perdus; dans le catalogue encore inédit de 1382 figurent 300 volumes seulement"); or en 1355 les documents nous permettaient d'en retrouver au moins 380. Donc, dès la fin du $14^{\mathrm{e}}$ siècle, la bibliothèque est en décroissance. Sans doute, en apparence du moins, elle a depuis lors réparé ses pertes: actuellement Patmos compte 735 manuscrits; mais plus de la moitié de ces volumes sont de date fort récente et ne sauraient remplacer les anciens exemplaires qu'on a laissé perdre misérablement. Sans doute aussi, pendant les siècles qui suivent le $14^{\mathrm{e}}$, des circonstances heureuses introduisent parfois encore des manuscrits intéressants au monastère. Au $15^{\circ}$ siècle, comme autrefois, de pieux donateurs se rencontrent parmi les higoumènes ${ }^{3}$ ); des îles voisines, de Naxos ${ }^{4}$ ), de Rhodes ${ }^{5}$ ), d'ailleurs encore, des livres émigrent à Patmos; enfin, l'abbaye s'enrichit quelquefois de la ruine des couvents de la côte asiatique et hérite de quelques unes de leurs dépouilles. ${ }^{6}$ ) Mais, pendant ce temps, les manuscrits anciens s'en vont à l'abandon. Ni les souvenirs historiques qui s'attachent à certains volumes, ni la place assignée à d'autres parmi les trésors de la bibliothèque ne les garantissent contre la ruine. Sur les cinquante-huit manuscrits mis en vedette par le catalogue de 1355 , vingt au moins ne se retrouvent plus aujourd'hui. Les livres d'aspect profane sont particulièrement maltraités: tous ceux qui figuraient dans les inventaires de 1201 ou de 1355 ont disparu, à l'exception de Nicéphore Chumnos et de Zonaras ${ }^{7}$ ), de Diodore de Sicile ${ }^{8}$ ) et de Platon. Encore ce dernier volume a-t-il pu, on le sait, être emporté en 1803 en Angleterre $^{9}$ ): preuve dernière de l'indifférence que professaient pour leurs manuscrits les moines de Patmos, également oublieux des enseignements de St. Christodule et de l'antique gloire de leur librairie.

1) Migne, loc. laud., no 27. 38. 48. 50. 56.

2) Sakkelion, p. $\iota \alpha^{\prime}$.

3) Sakkelion, p. 53-54.

4) Sakkelion, no 50 et 57 .

5) Ibid, no 207.

6) Ibid., p. 122-123. no 78. 242. 244.

7) Sakkelion, no 127. 298.

8) Ibid, no 50 .

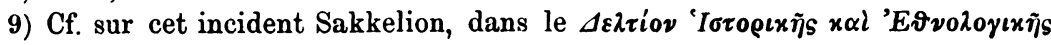

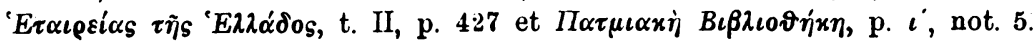


III.

Le registre des prêts.

En quelques endroits de l'inventaire, une seconde main a ajouté à la marge des notes indiquant que tel ou tel volume a été emprunté à la bibliothèque, et ces indications, répétées et complétées au verso du manuscrit, constituent un véritable registre des prêts faits par la librairie de Patmos. Les renseignements que nous y trouvons se rapportent pour la plupart à une époque un peu postérieure à la rédaction de l'inventaire: à la vérité, nous ignorons la date de l'higouménat de $\mathrm{Ni}$ codemos, dont le nom accompagne les dernières lignes du registre; mais nous pouvons tirer du texte même de suffisantes informations chronologiques. Parmi les emprunteurs assez nombreux qui viennent puiser aux richesses de la bibliothèque, deux établissements monastiques semblent traités avec une faveur particulière: la métochie de Pyrgos reçoit d'un seul coup onze volumes, celle de Cos, dix, et dans les deux cas, les manuscrits prêtés sont de même nature; c'est une série à peu près complète des livres liturgiques, comme si Patmos avait voulu fournir à ses deux métochies les textes indispensables à la célébration de l'office divin. ${ }^{1}$ ) Or nous savons à quelle date les deux couvents en question sont entrés dans le domaine de l'abbaye. Pyrgos lui a été donné en 1216 par l'empereur Théodore Lascaris ${ }^{2}$ ); le monastère de la Theotokos $\tau \tilde{\omega} \nu \Sigma \pi 0 \nu \delta \tilde{\omega} \nu$ à Cos parait lui avoir été attribué sous le règne de Jean Vatatzès $(1222-1254) .^{3}$ ) C'est sans doute au moment de la prise de possession des deux métochies que les livres nécessaires leur furent remis par la bibliothèque, et nous pouvons en conséquence placer avec grande vraisemblance l'higoumène Nicodemos immédiatement avant Germanos, que nous trouvons en 1258 occupé à achever l'organisation de la métochie de $\operatorname{Cos}^{4}$ ) Les prêts de manuscrits enregistrés dans notre document doivent donc être rapportés à la première moitié du $13^{e}$ siècle. $^{5}$ )

1) C'est dans le même esprit que l'higoumène Sabas légue à l'église roṽ

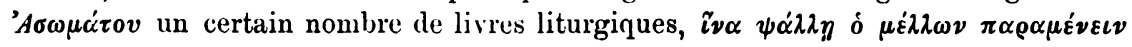
Éxeió (Acta, p. 242).

2) Acta, p. 176. 180. 199.

3) Cf. Acta, p. 217.

4) Acta, p. 193.199.

5) On peut serrer de plus près encore la date des derniers prêts inscrits au registre et consentis sous l'higouménat de Nicodemos en faveur de la métochie de Cos. Ils portent l'indication chronologique de l'indiction 2. Or, sous le règne de Jean Vatatzès, deux dates seulement correspondent à cette indiction: ce sont les années 1229 et 1244. 
A cette époque, la bibliothèque de Patmos était pour toute la région environnante un véritable foyer de haute culture intellectuelle. Non seulement elle fournissait de livres les dépendances immédiates du monastère, telles que la métochie de Leros, acquise dès l'époque de Christodule, celle de St. Georges $\tau$ $о \tilde{v} \Delta v \sigma \iota x o \tilde{v}$, sise dans le petit port asiatique de $\mathrm{Phygela}^{1}$ ), celle de St. Pantéléimon, près de Palatia, également sur la côte asiatique ${ }^{2}$ ), celle de Pyrgos près du Méandre ${ }^{3}$ ), celle de la Theotokos $\tau \tilde{\omega} \nu \Sigma \tilde{\Sigma} 0 \nu \delta \tilde{\omega} \nu$ à $\operatorname{Cos}^{4}$ ), celle de St. Nicétas de Psychros en Crète $^{5}$ ); mais encore tous les établissements religieux du voisinage venaient faire des emprunts à la riche librairie du couvent. Le monastère de St. Mercure à Palatia la mettait à contribution; l'abbaye de St. Paul du Latros, jadis dépouillée par Christodule, demandait des livres à son heureuse rivale et obtenait, non seulement le prêt, mais parfois même la restitution gracieuse de certains manuscrits. $^{6}$ ) Les moines de Strobilos, près d'Halicarnasse, qu'unissait à Patmos le souvenir de St. Christodule ${ }^{\top}$ ), les anachorètes de Calymnos, les prêtres du clergé séculier de Samos figuraient également parmi les emprunteurs. Enfin les simples particuliers mêmes, que leur situation personnelle ou leur parenté avec quelqu'un des moines recommandaient à la bienveillance du couvent, étaient libéralement admis au privilège du prêt. Avec les familles riches de Palatia les relations étaient fréquentes, et pour faire plaisir au moine Maximos, on envoyait à son père des livres jusqu'en Crète.

En général pourtant les manuscrits empruntés sont des livres purement liturgiques. Sur 45 volumes sortis, trente-quatre appartiennent à cette catégorie. $\left.{ }^{8}\right)$ Les autres volumes prêtés sont des vies de saints (4 fois), des écrits des Pères (Chrysostome, 2 fois; André de Crète,

1) Acta, 174. Cf. 179. 182.

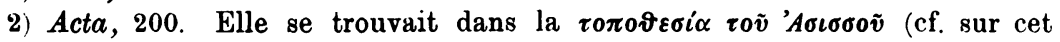
endroit, Acta, 167. 168. 169).

3) Acta, 177. 199.

4) Acta, 184. 193. 200.

5) Acta, p. 131. Cf. sur l'emplacement de ces établissements les notes de la p. 524 .

6) Omont, Note sur un ms. du Mont Latros, loc. laud., p. 338.

7) Acta, 62.

8) Voici le détail de ces prêts:

Triodion (4 fois)

Octoïchos (5 fois)

Ménées (11 fois)

Evangiles (3 fois)

Euchologe (2 fois)

Kontakia (2 fois)
Paterikon (2 fois)

Apôtre (1 fois)

Eortologion (1 fois)

Psautier (1 fois)

'Axodovvía (1 fois)

Schematologion (1 fois) 
1 fois; Evergetikon, 1 fois), des traités d'édification (Climaque, 2 fois) et un manuscrit de Job. Les auteurs profanes n'ont tenté la curiosité d'aucun des correspondants du couvent.

Ces indications, si peu nombreuses qu'elles soient, permettent cependant d'entrevoir la place considérable que Patmos mérite dans l'histoire littéraire du moyen-âge oriental. Sur les côtes de l'Anatolie grecque, dans ces îles de l'Archipel, si durement éprouvées par des misères de toute sorte, les moines de Patmos ont, pendant plusieurs siècles, allumé un dernier rayon de vie intellectuelle. Pour ces pieuses communautés, pour ces humbles bourgades réfugiées sous la protection du saint patron de l'abbaye, le couvent de St. Jean le Théologue n'a pas été seulement un centre religieux, il est demeuré un foyer vivant de culture et de civilisation. En dotant d'une bibliothèque son monastère bien aimé, Christodule n'avait donc point fait une œurre vaine; en poursuivant pendant près de trois siècles l'accroissement de la primitive librairie, ses successeurs n'avaient point tenté des efforts stériles. Sans doute le résultat final n'a point pleinement répondu à leurs espérances; sans doute la négligence des siècles suivants a laissé disparaitre beaucoup de ces volumes qu'ils avaient si laborieusement rassemblés. On n'en doit pas moins savoir gré aux moines du $11^{\mathrm{e}}$ et du $12^{\mathrm{e}}$ siècle d'avoir su unir aux soucis de la foi ces nobles et sérieuses préoccupations: elles leur assurent une grande place dans l'histoire des lettres, elles leur méritent aujourd'hui encore notre reconnaissance et notre respect.

\section{Appendice.}

Nous publions en appendice le texte inédit de l'Inventaire de 1201 qui a servi de base à nos recherches sur la bibliothèque de Patmos.

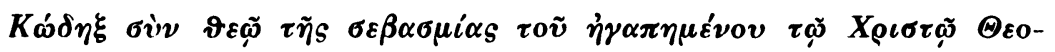

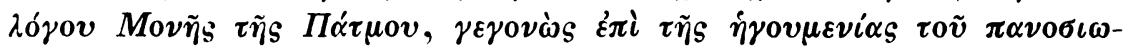

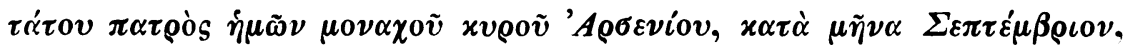

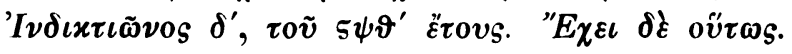

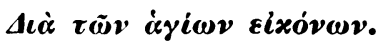

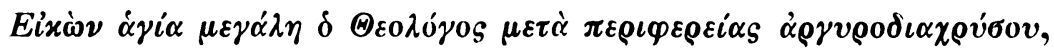

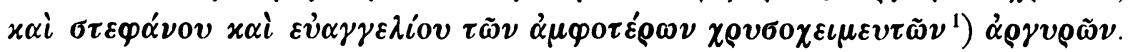

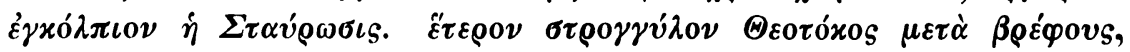

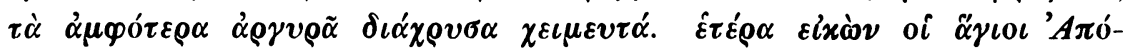

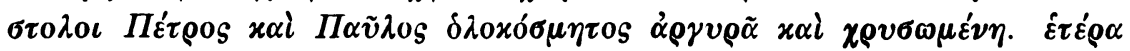

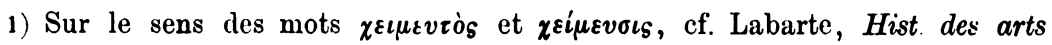
indus̀triels, t. III, p. 74-76. 


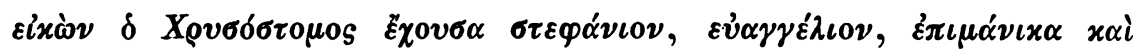

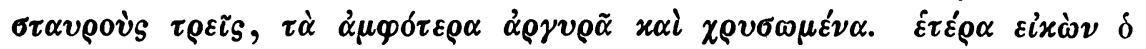

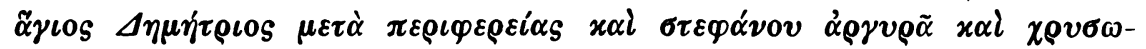

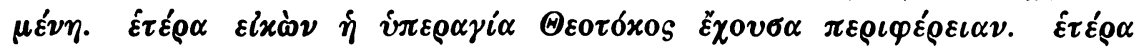

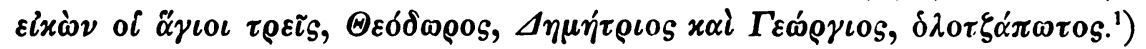

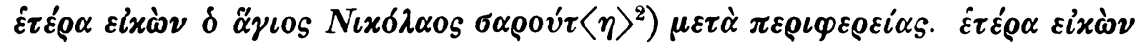

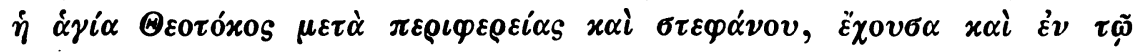

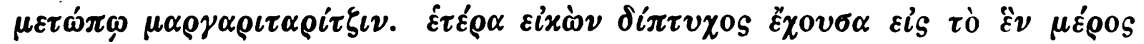

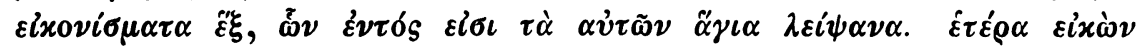

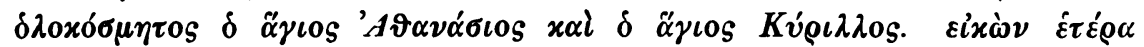

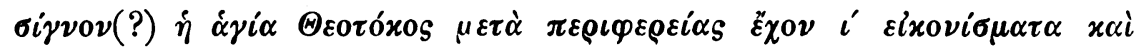

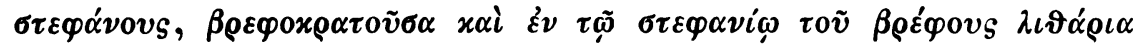

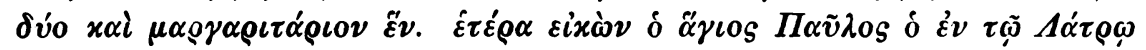

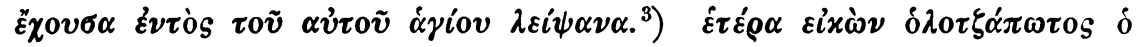

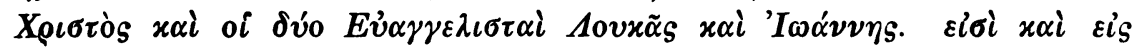

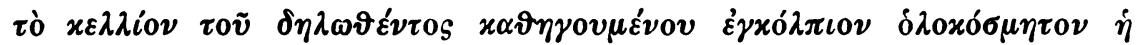

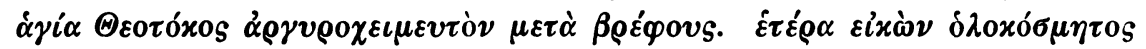

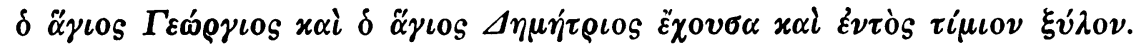

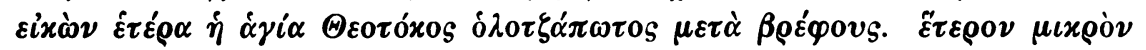

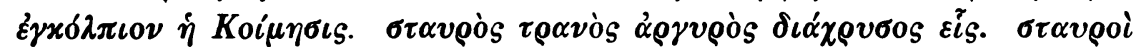

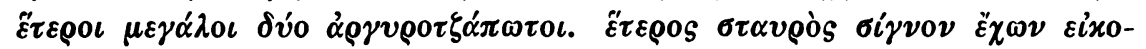

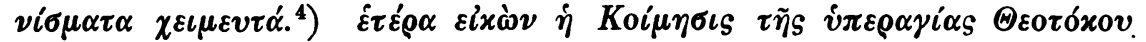

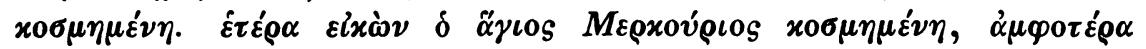

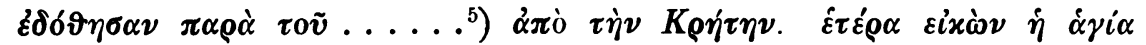

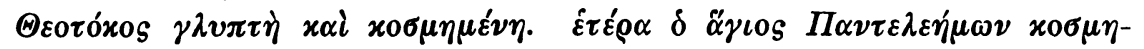
$\left.\mu \varepsilon \dot{v} \nu v^{6}\right)$

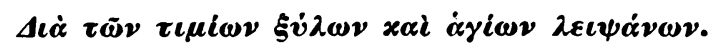

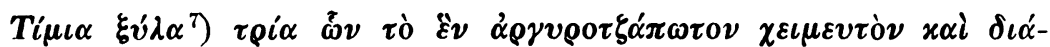

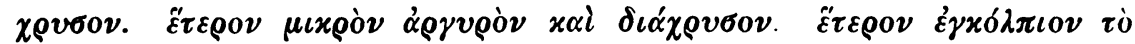

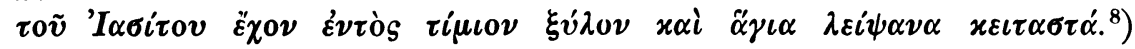

1) $T \zeta \alpha_{\alpha}^{\prime} \pi \omega \tau 0 S=$ clavatus (Ducange).

2) Cf. sur ce mot l'inventaire de Michel Attaliote (Sathas, p. 48). Le mot

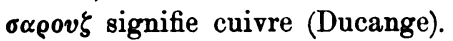

3) Sur St. Paul du Latros, cf. Acta Sanct., Oct. t. XI, p. 308. Cf. Analecta Bolland., t. XI (1892 fasc. 1 et 2, où se trouve la vie du saint.

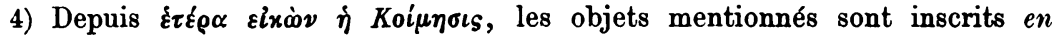
marge de l'inventaire.

5) Blanc dans le manuscrit.

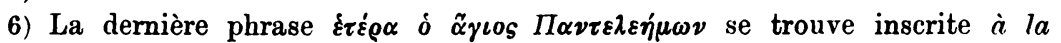
marge, comme les précédentes, mais d'une autre main.

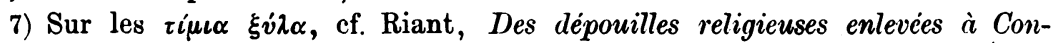
stantinople, p. 17 et $28 . \quad$ 8) Sur ces phylactères, Riant, ibid., p. 28. 


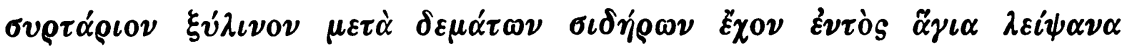

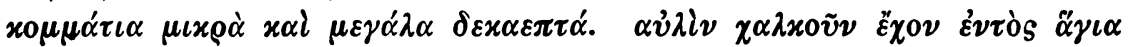

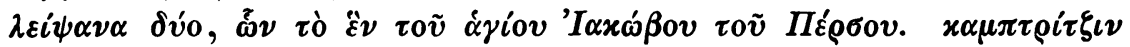

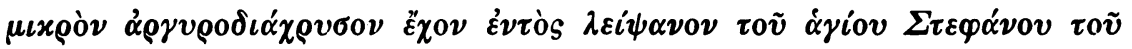

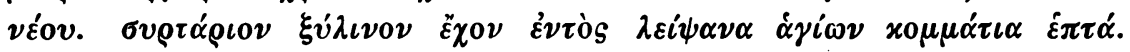

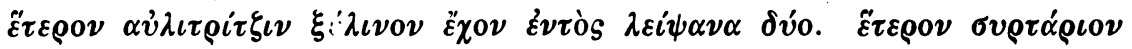

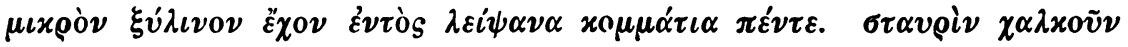

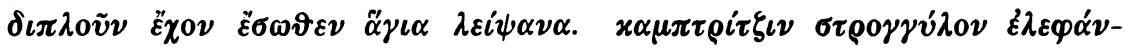

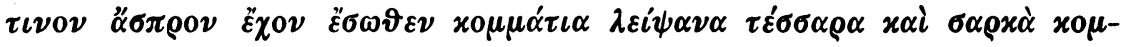

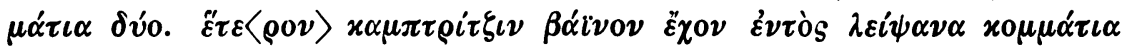

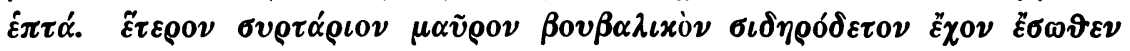

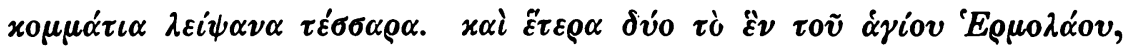

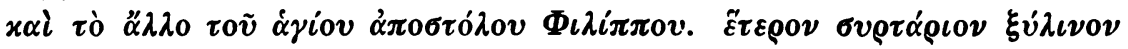

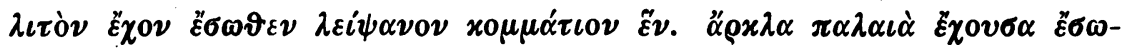

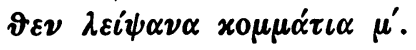

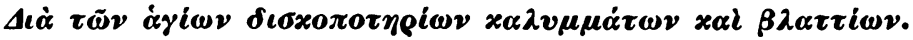

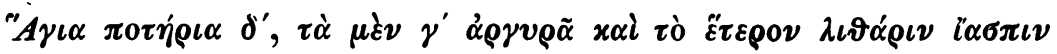

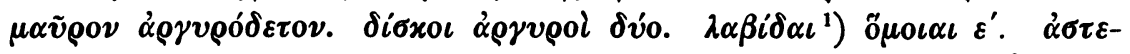

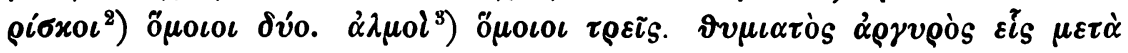

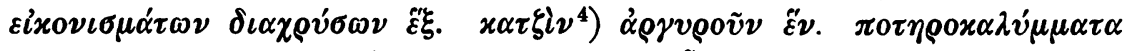

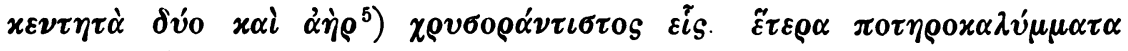

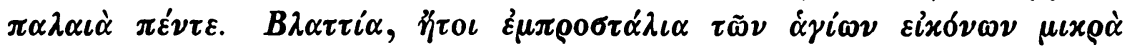

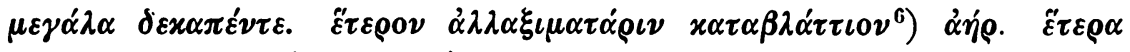

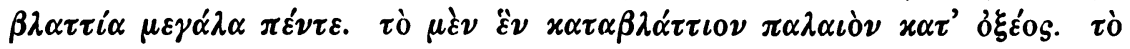

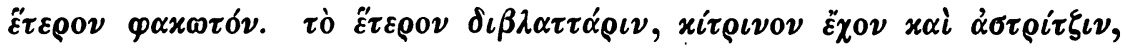

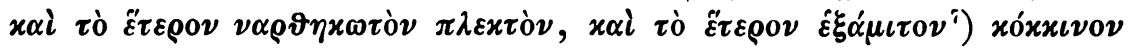
$\mu \varepsilon \tau \grave{\alpha}$

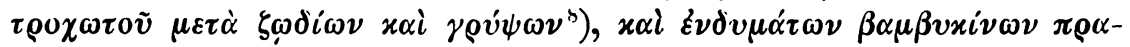

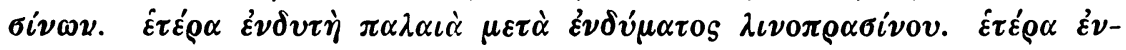

1) Petite cuiller pour extraire le pain du calice, et à l'aide de laquelle on donne la communion aux fidèles.

2) Petit arc destiné i empêcher le contact entre l'hostie et l'étoffe qui recouvre la patène.

3) Cf. l'inventaire d'Attaliote (Sathas, p. 48) où on lit $i \boldsymbol{v}_{\mu}$ òs.

4) Cassolette pour l'encens.

5) Étoffe qui sert à couvrir ì la fois le calice et la patène (Sopho cles Greek Lexikon, v. $x \alpha \dot{\alpha} v \mu \mu \alpha)$.

6) Sur le $x \alpha \tau \alpha \beta \lambda \alpha ́ \tau \tau \iota \nu \nu$, cf. Francisque Michel, Recherches sur le commerce, la fabrication et l'usage des étoffes de soie, d'or et d'argent, t. I, p. 12.

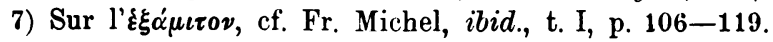

8) Sur ces étoffes historiées, cf. Labarte, II, 424-426. 


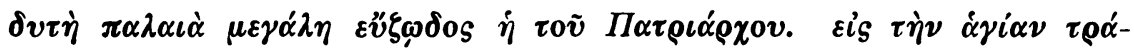

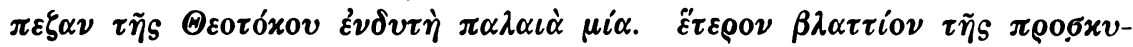

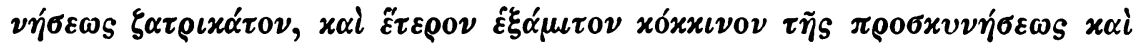

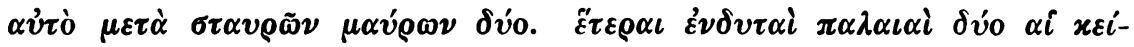

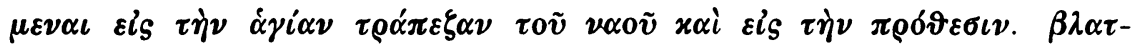

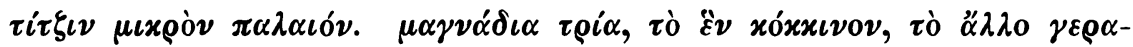

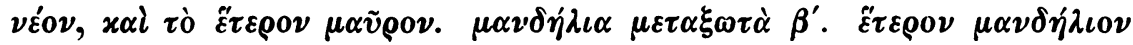

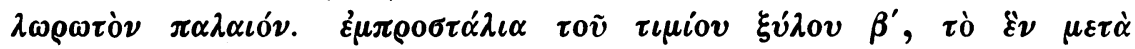

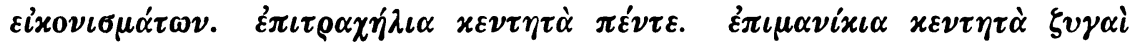

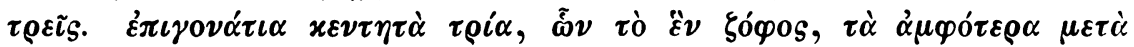

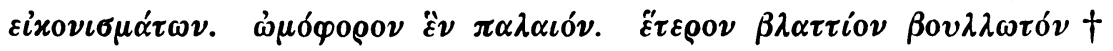

\section{$\Delta \iota \dot{\alpha} \tau \tilde{\omega} \nu \beta \iota \beta \lambda i \omega \nu .1)$}

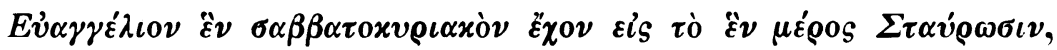

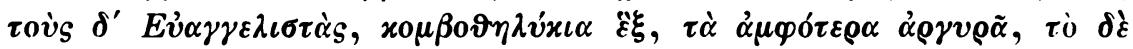

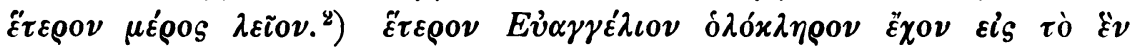

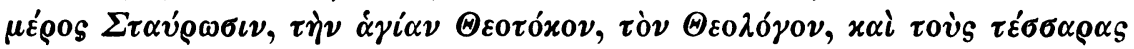

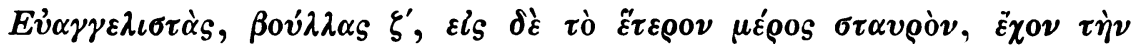

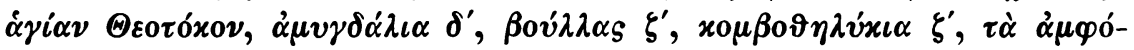

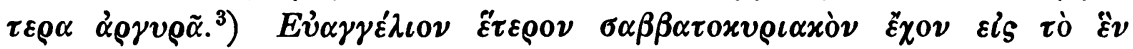

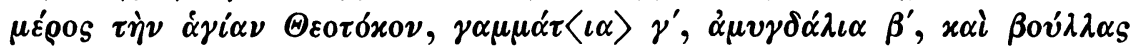

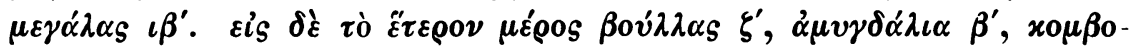

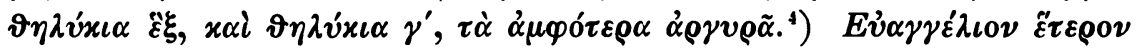

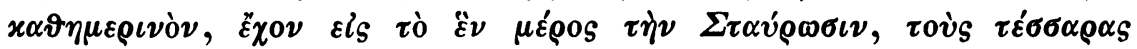

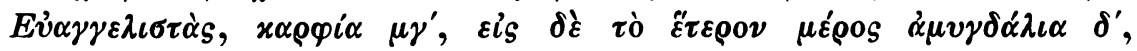

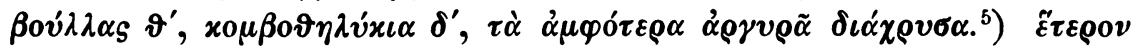

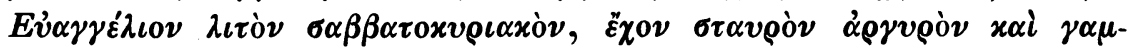

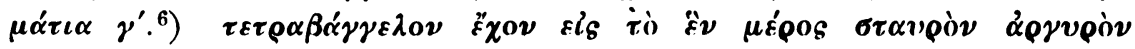

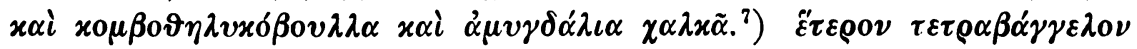

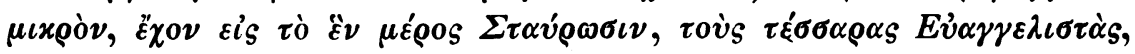

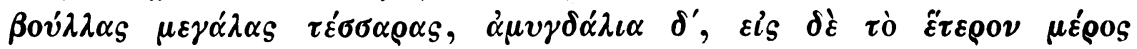

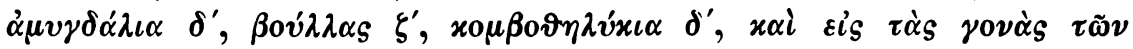

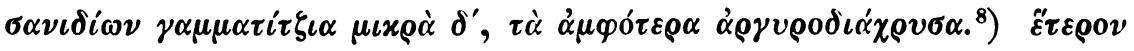

1) Nous nous sommes efforcé de déterminer ceux d'entre ces manuscrits qui figurent encore dans la bibliothèque de Patmos. Nous indiquons en note, pour tous ceux où l'identification est certaine ou probable, les numéros correspondants du catalogue de Sakkelion; un point d'interrogation désigne les identifications qui semblent seulement vraisemblables.
2) no $69(?)$.
3) no 74.
4) no $70(?)$.
5) no $79(?)$.
6) no. $71(?)$.

7) no. $90(?)$. 8) no 274 . 


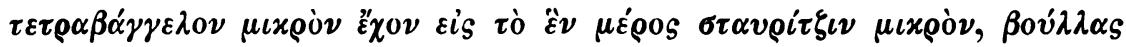

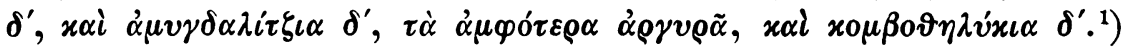

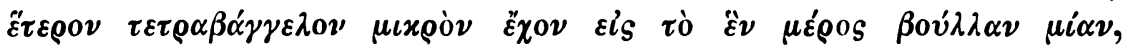

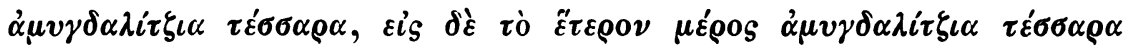

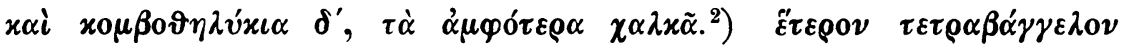

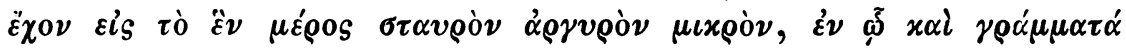

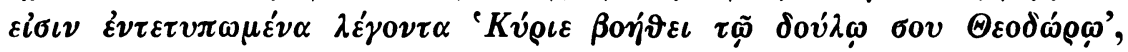

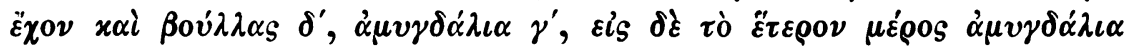

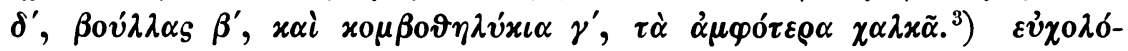

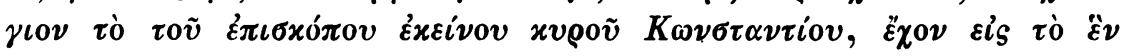

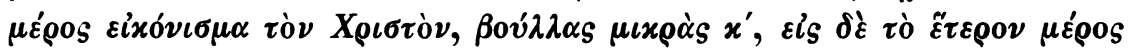

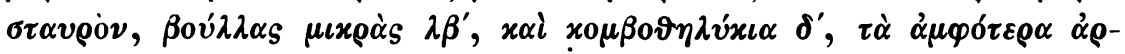

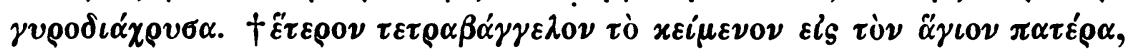

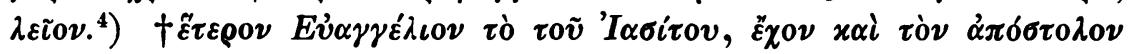

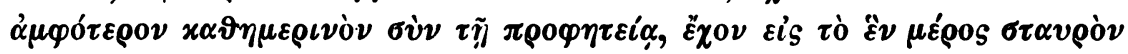

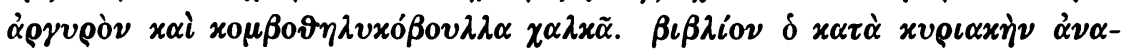

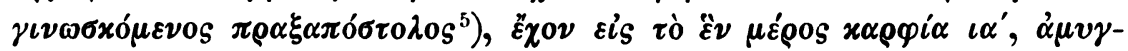

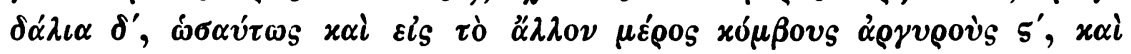

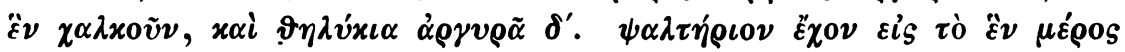

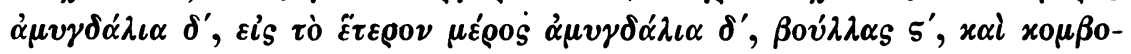

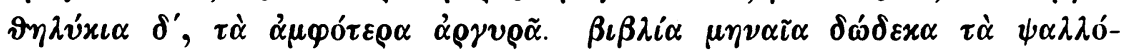

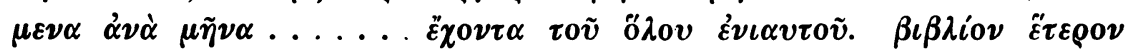

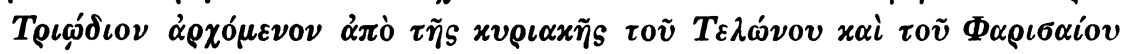

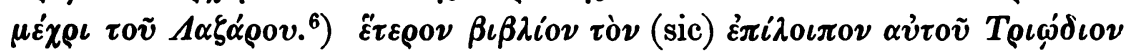

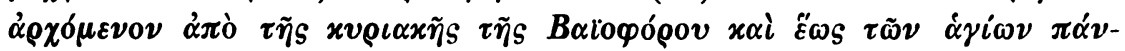

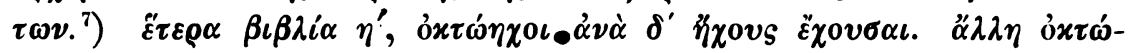

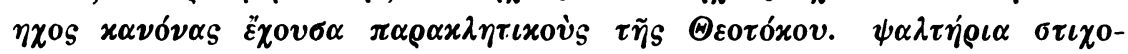

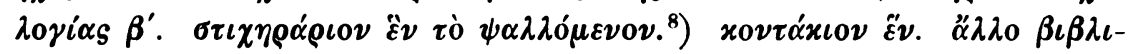

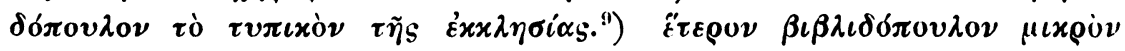

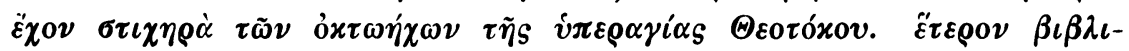

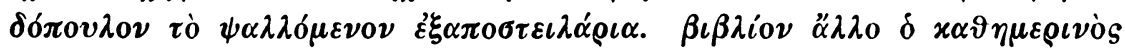

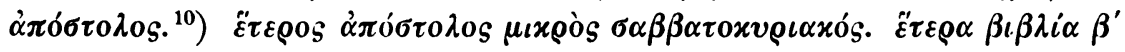

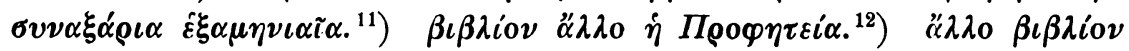

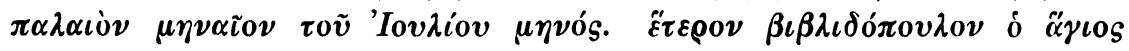

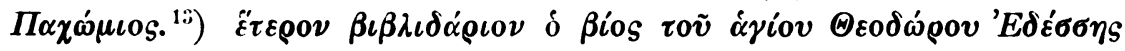

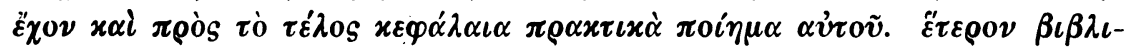

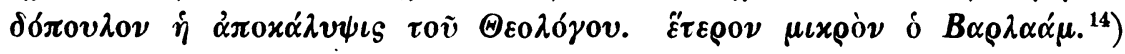
1) no. $82(?)$.
2) no $83(?)$.
3) no $80(?)$.
4) no $67(?)$.
5) no $15($ ?).
6) no $212(?)$.
7) no $213(?)$.
8) no $218(?)$.
9) no 267 (?).
10) no 11.
11) no 261 et $: 262$.
12) no 210.
13) no 9.
14) no 8. 


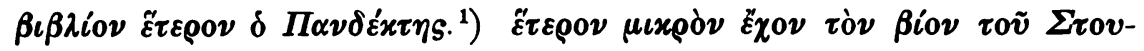

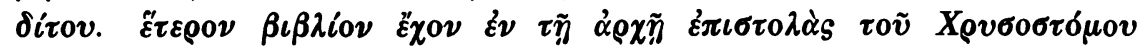

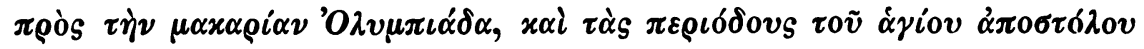

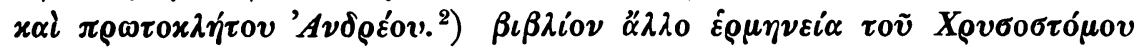

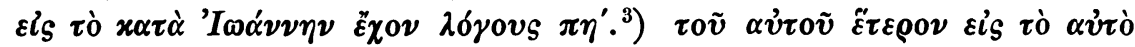

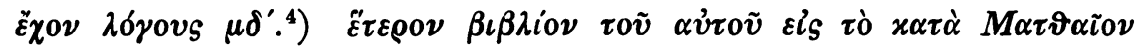

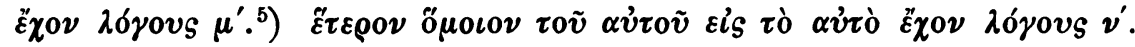

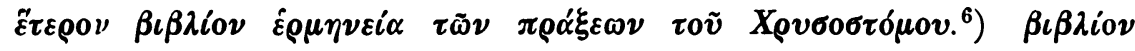

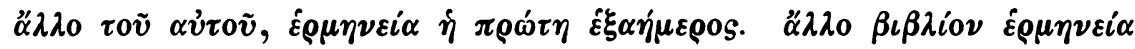

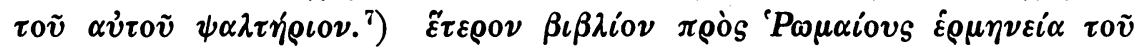

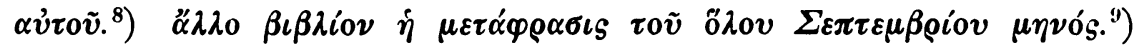

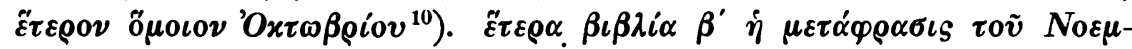

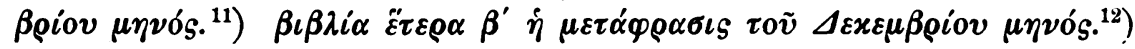

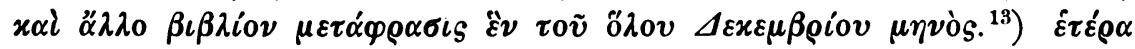

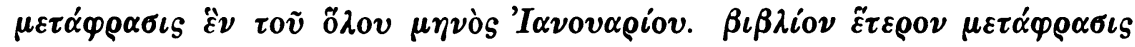

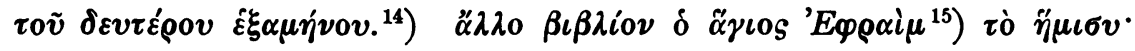

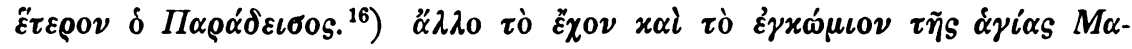

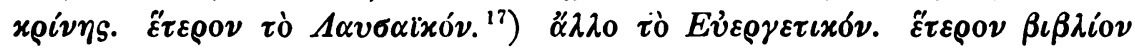

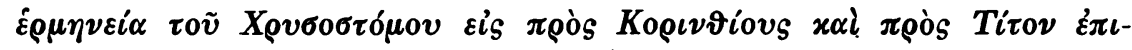

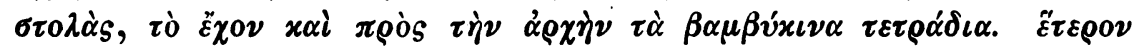

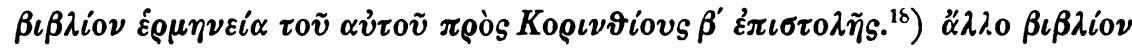

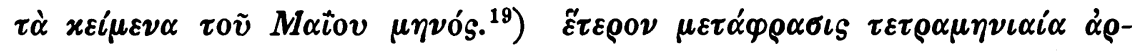

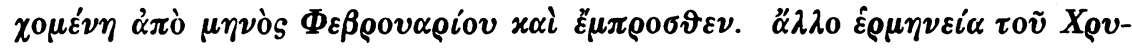

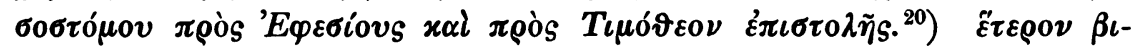

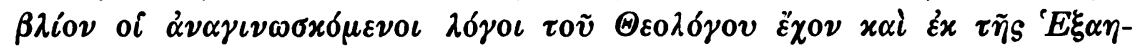

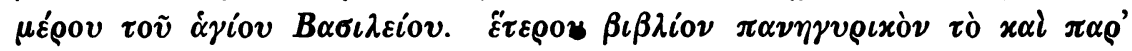

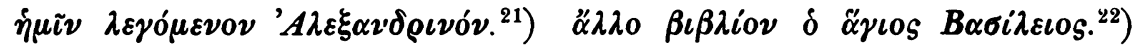

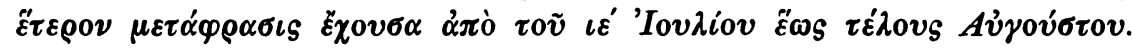

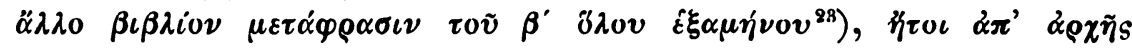

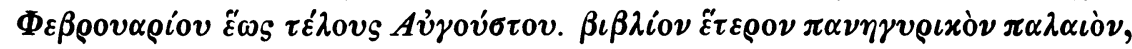

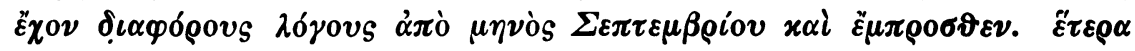

1) Il y a un livre de ce nom composé par St. Nicon, moine de Raitha en Palestine (Fabricius, Bibl. graeca, ed. Harles, t. XI, p. 275-278). Cf. aussi pour un autre $\Pi \alpha \nu \delta \varepsilon \dot{x} \tau \eta$, Sakkelion, loc. laud., p. 144-145. Ce livre se trouve aussi dans la bibliothèque de Michel Attaliote (Sathas, loc. laud., p. 49).
2) no 162 .
3) no 128.
4) no 141 .
5) no 168.
6) no 150 .

7) no $159($ ?). $\quad$ 8) no $145(?)$ 9) no 228 . 10) no 250 . 11) no 230 et 231.
12) no 240 et 243.
13) no 241.
14) no 255 .
15) no 107.
16) Sur le

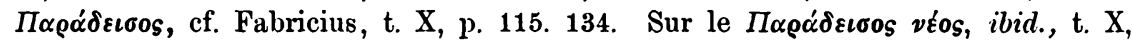

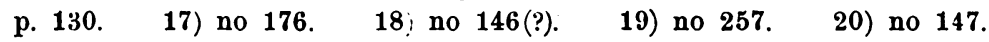

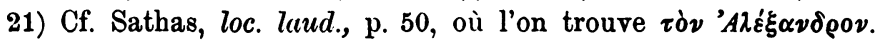

22) no $27(?)$. 23) no 259 . 


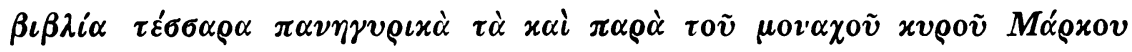

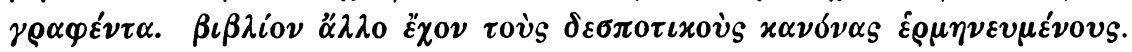

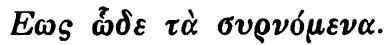

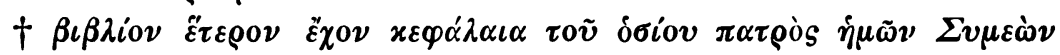

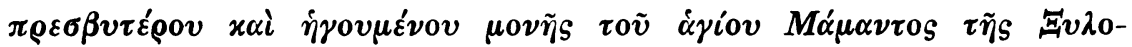

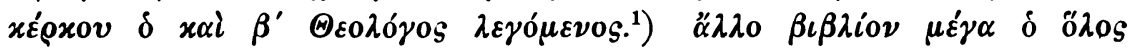

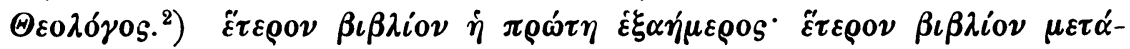

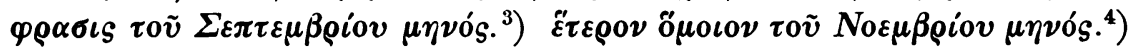

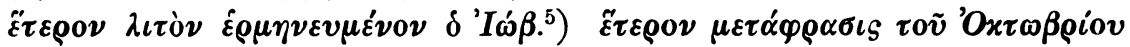

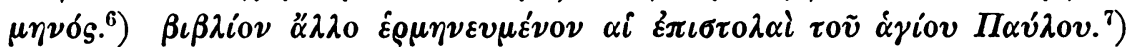

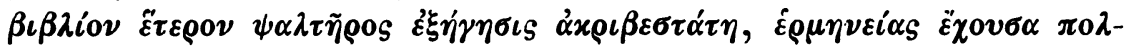

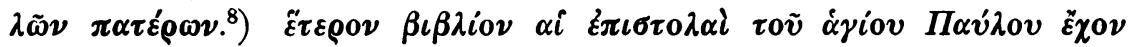

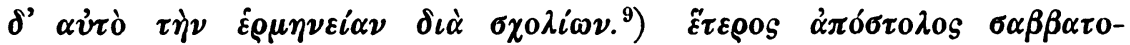

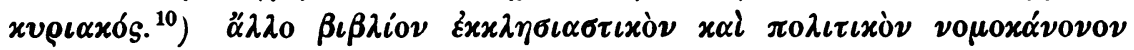

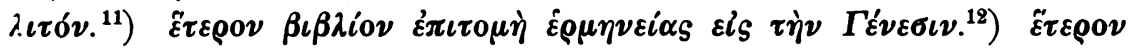

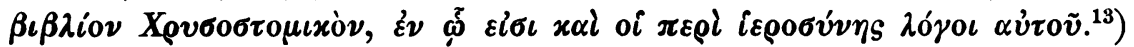

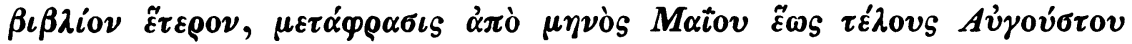

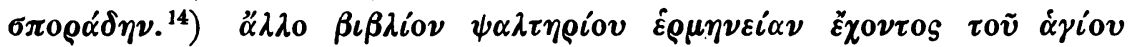

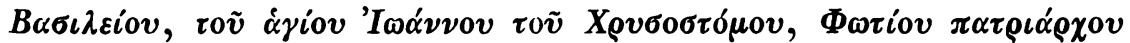

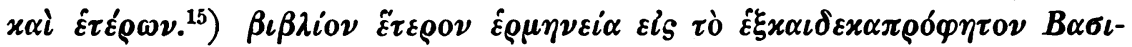

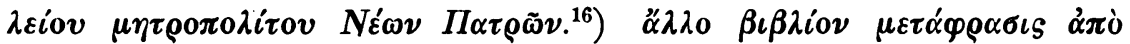

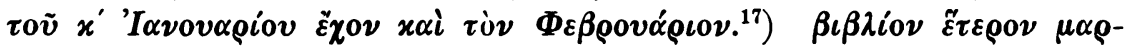

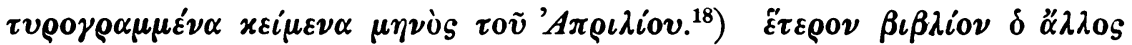

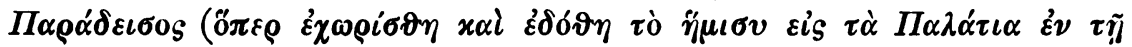

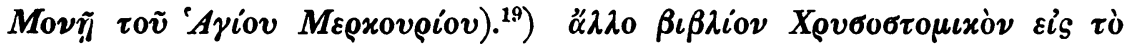

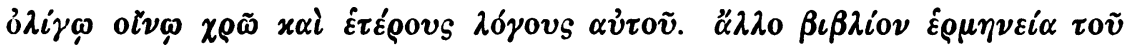

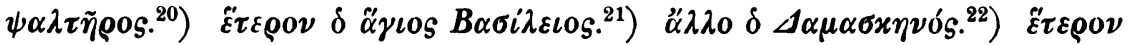

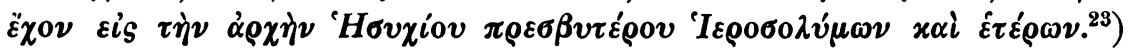

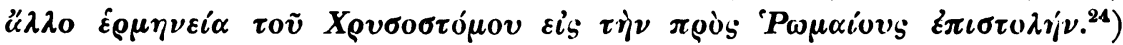

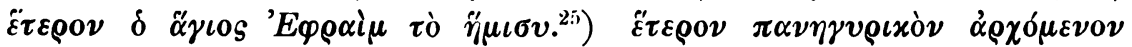

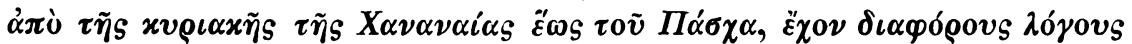

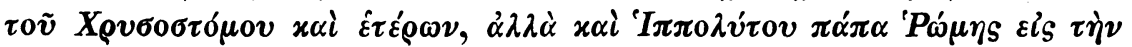

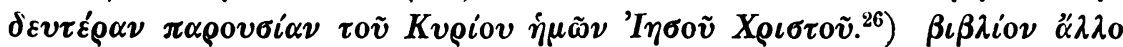

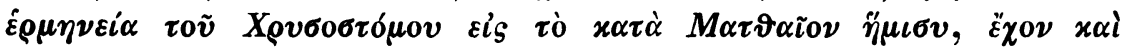

1) Sur ce personnage, ef. Fabricius, II, 302 et Sakkelion, p. 177. 188.
2) no 33 .
3) no 249.
4) no 235 .
5) no 171.
6) no 251 .
7) no 61 .
8) no 65 (?).
9) no 63 (?).
10) no 16 (?).
11) no 173 (?).
12) no 177 (?)
13) no 170 (?).
14) no 256 .
15) no 66
16) no 31 .

17) no 247. 18) no 254 . 19) La phrase entre parenthèses est écrite d'une autre main à la marge du ms. 20) no 269 (?). 21) no 24 . 22) no 125.23 ) no 109. 24) no 62 . 25) no 106 . 26) no 186. 


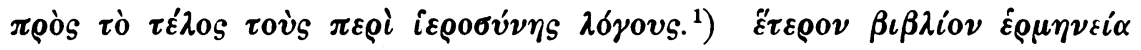

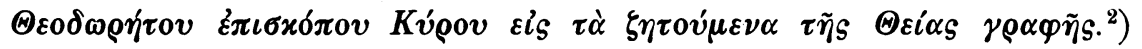

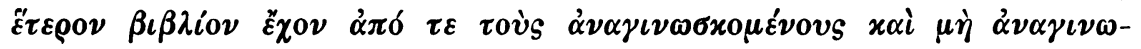

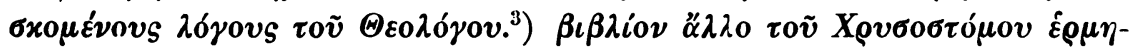

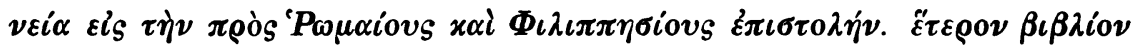

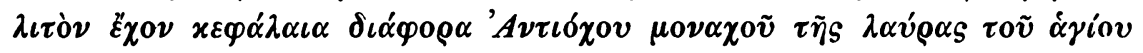

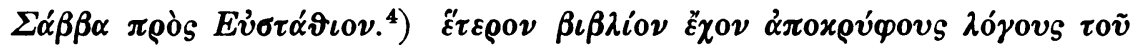

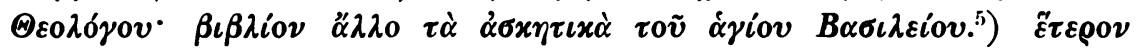

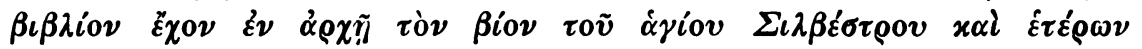

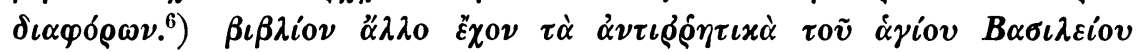

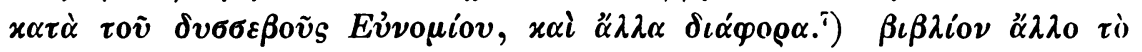

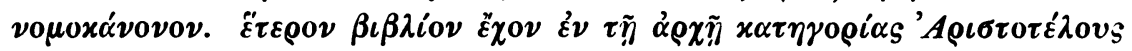

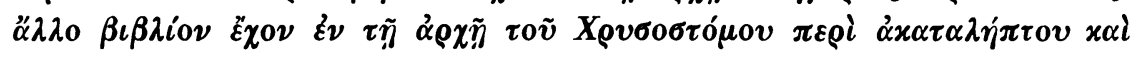

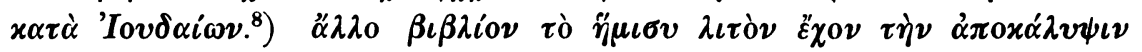

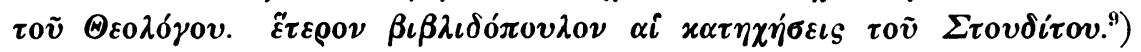

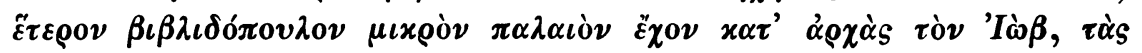

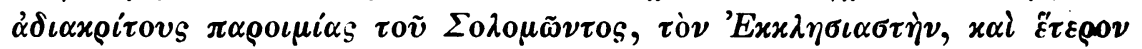

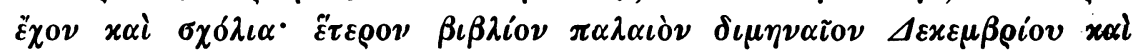

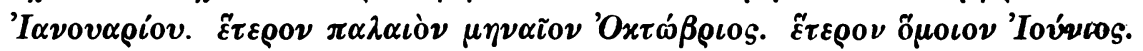

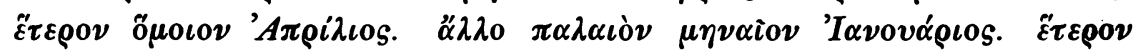

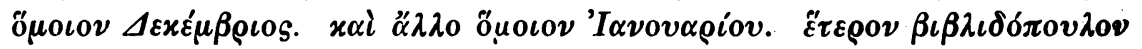

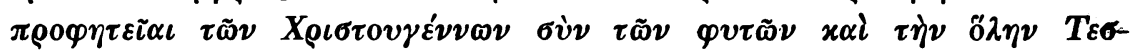

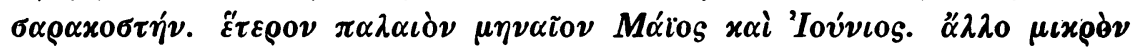

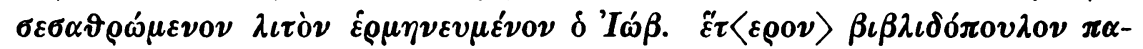

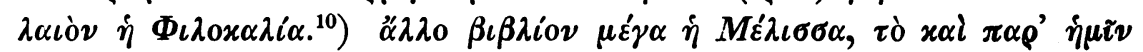

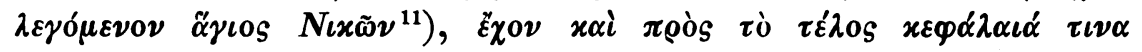

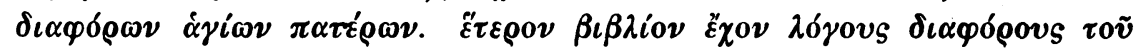

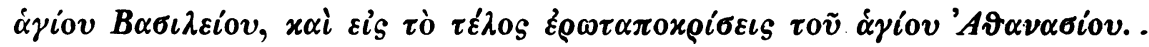

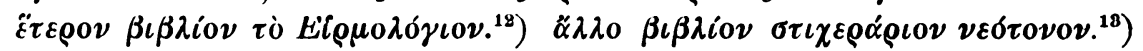

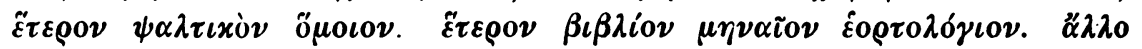

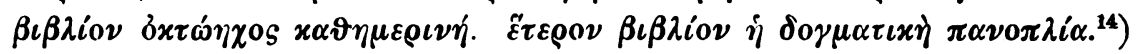

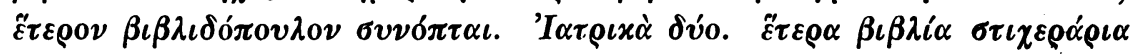

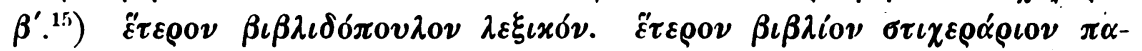

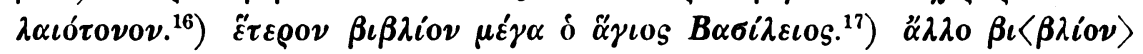

1) no 138 . 2) no 114 3) no 37.

4) Cf. Duchesne et Bayet, Mission au Mont-Athos (Arch. des missions,

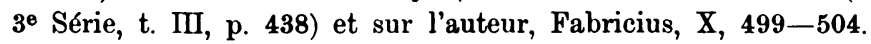

5) no 20 . 6) no $183 . \quad 7)$ no $184 . \quad 8)$ no 152 . 9) no 112 10) no 270.

11) Sur la Melissa du moine Antoine, Krumbacher, Gesch. d. byz. Litt., 289.

12) no 54. 13) Sakkelion, p. 119 . 14) no $102 . \quad 15)$ Sakkelion, p. 119.

16) ibid. 17) no 18. 


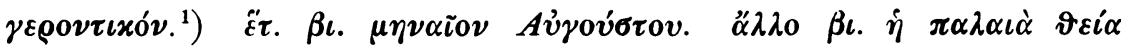

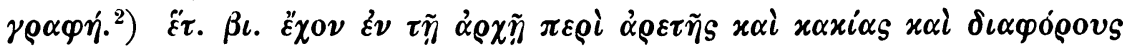

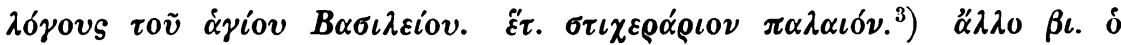

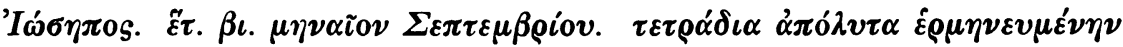

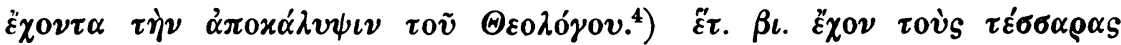

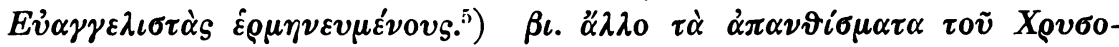

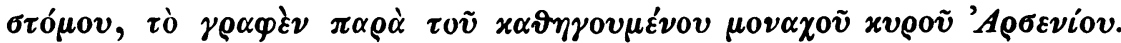

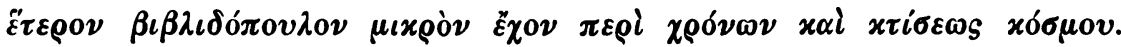

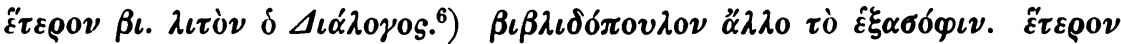

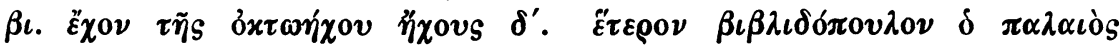

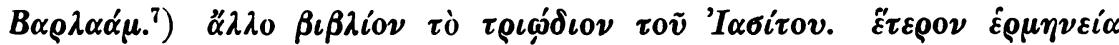

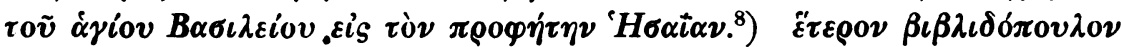

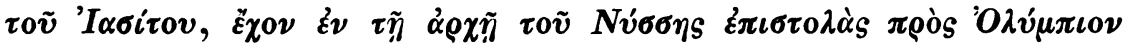

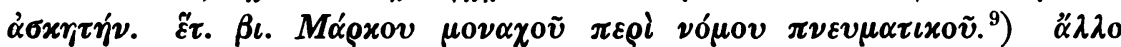

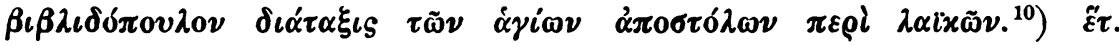

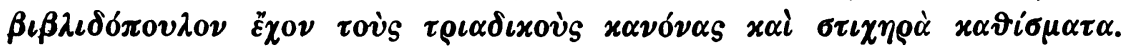

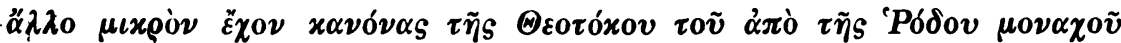

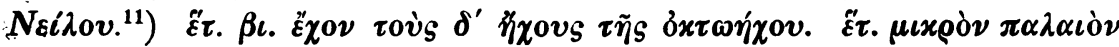

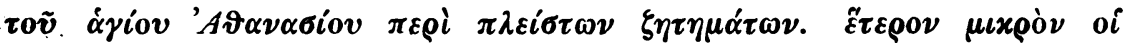

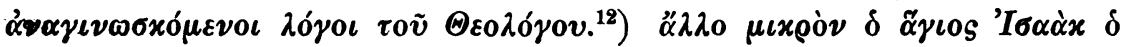

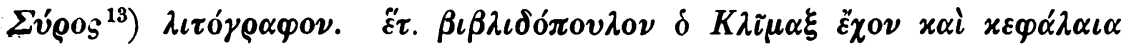

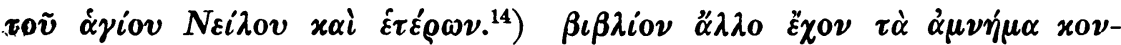

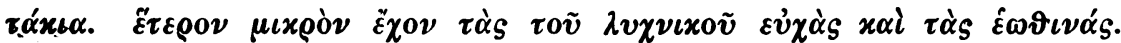

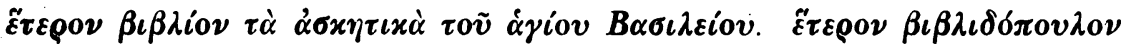

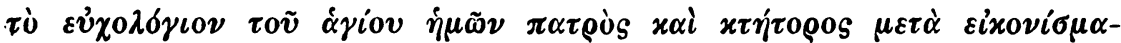

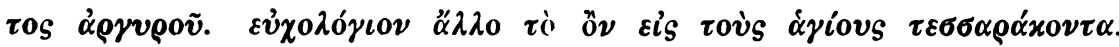

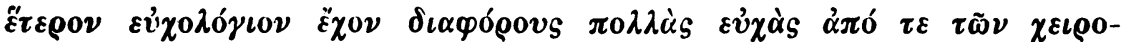

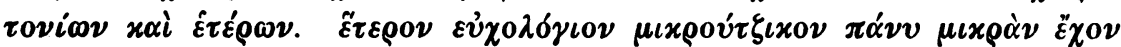

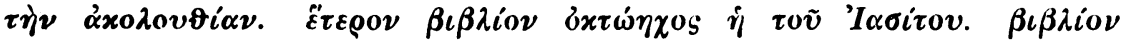

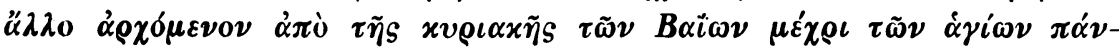

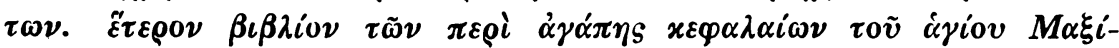

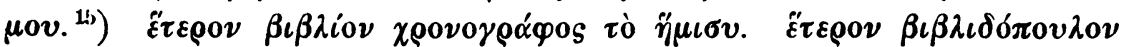

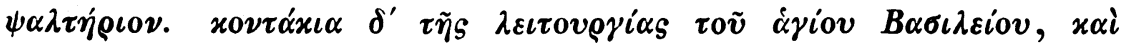

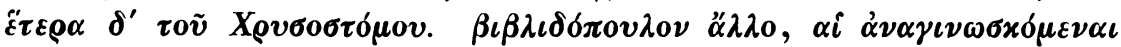

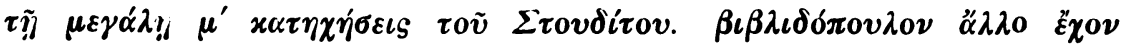

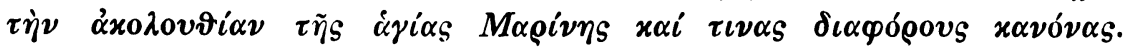
1) Sur cet ouvrage, Fabricius, $X, 128-129$.
2) no 216 (?).
3) Sakkelion, $\begin{array}{lllllll}\text { p. } 119.4) \text { no } 64 \text {. 5) no } 58 \text {. 6) no } 48 \text {. 7) no } 120 \text {. 8) no } 26 . \quad 9) & \text { no } 193\end{array}$ et sur l'auteur, Fabricius, IX, 267. Cf. aussi no 48. 10) no 174.11 ) no 175. 12) no 34. 13) Cf. Fabricius, XI, 119 et Sakkelion, p. 162.14 ) no 122. 15) Cf. no 48 . 


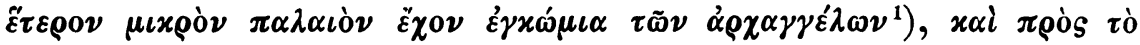

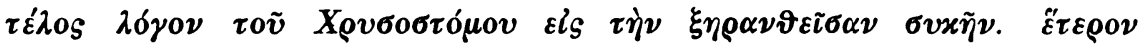

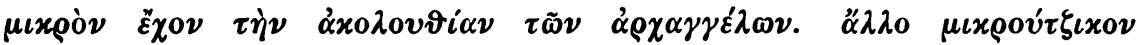

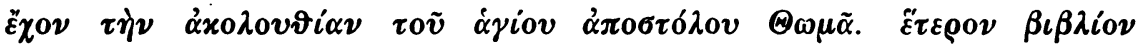

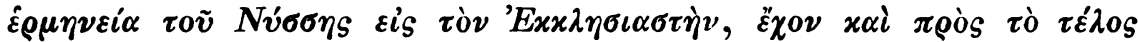

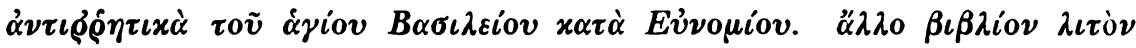

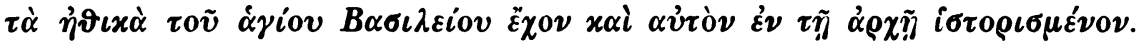

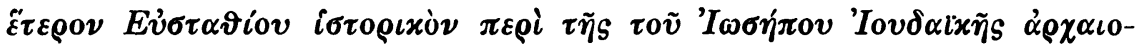

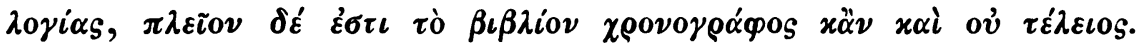

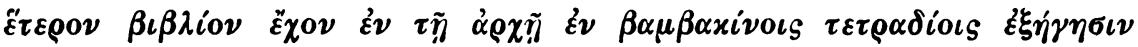

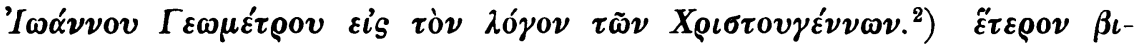

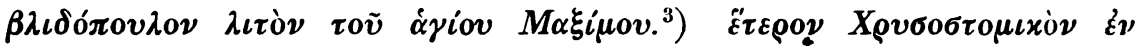

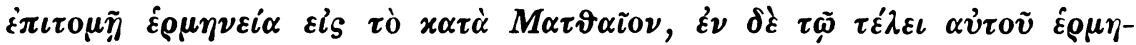

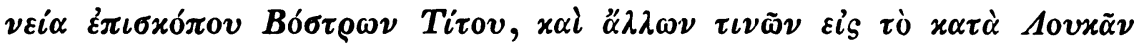

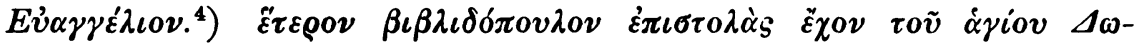

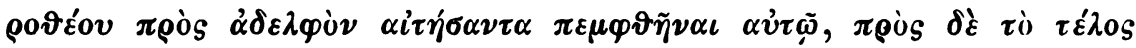

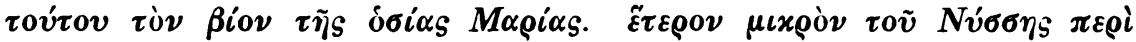

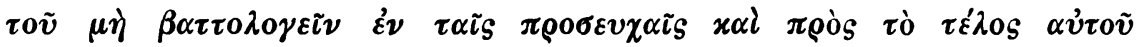

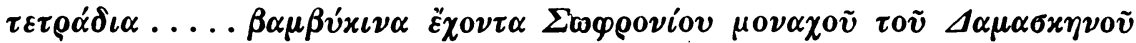

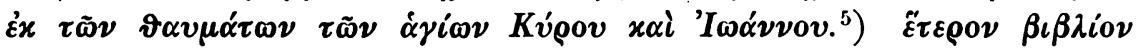

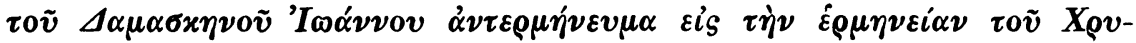

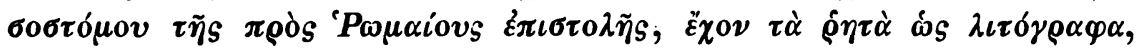

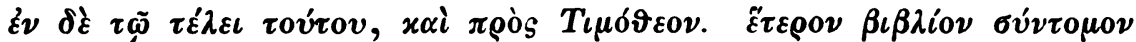

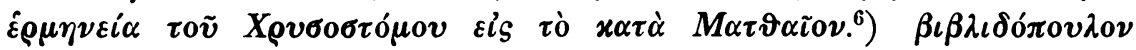

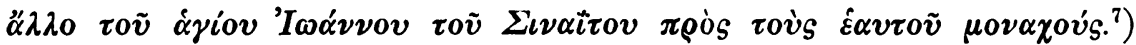

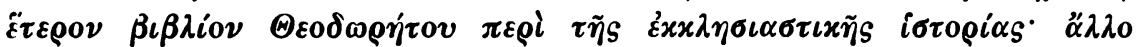

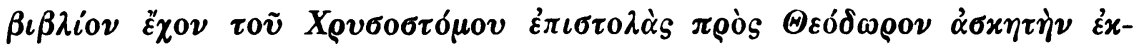

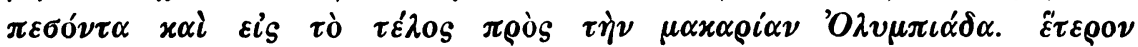

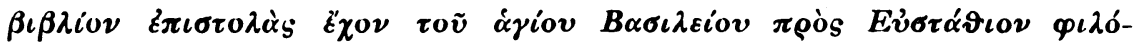

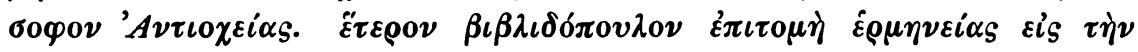

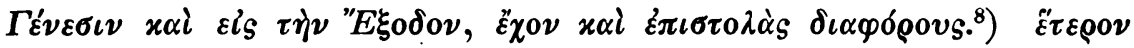

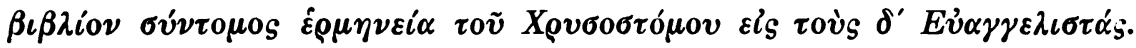

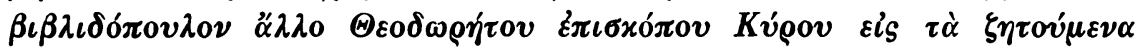

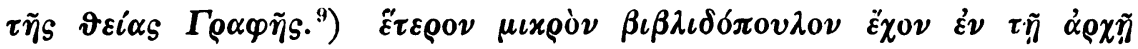

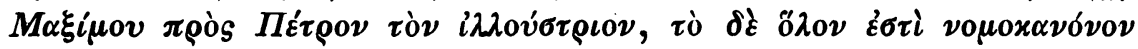

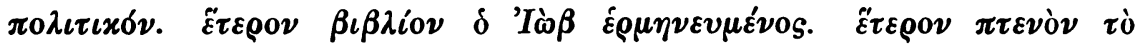

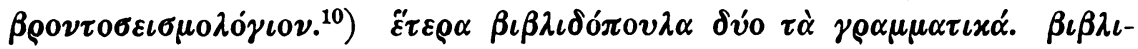

1) Sur cet ourrage, Fabricius, IX, 165.

2) Cf. Sakkelion, p. 12, no 25.
3) no 192.
4) no 59 .
5) Sur Sophronius, cf. Fabricius, IX, 164.
6) no 60 .

7) no 121.

8) no 178.

9) no 10.

10) Cf. Sathas, loc. laud., p. 50, où l'on

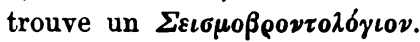




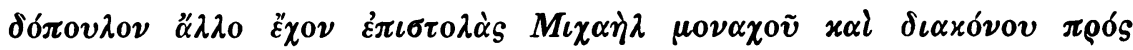

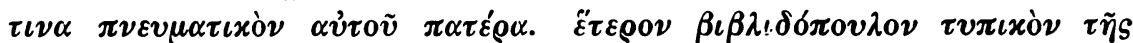

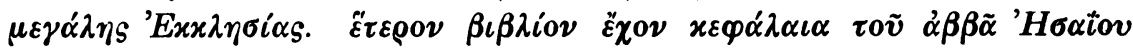

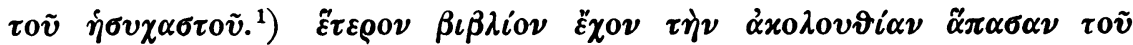

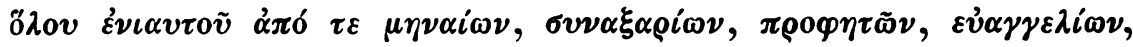

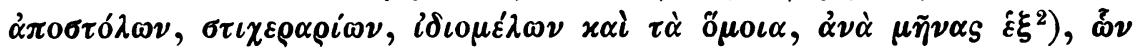

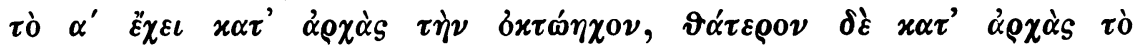

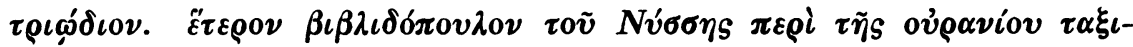

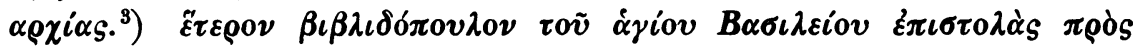

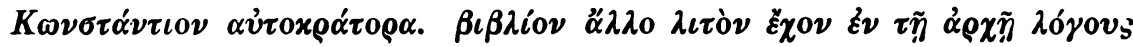

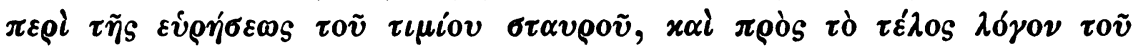

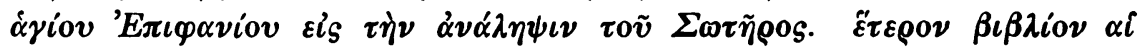

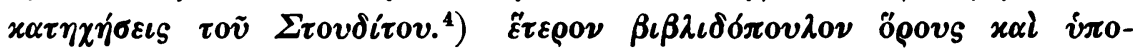


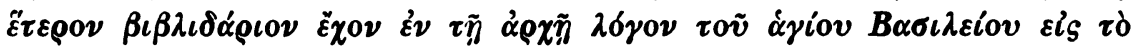

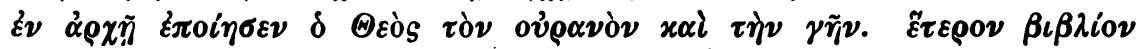

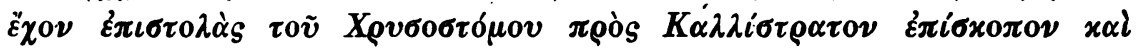

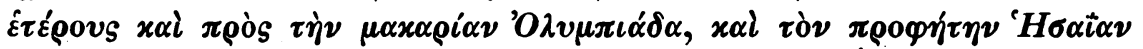

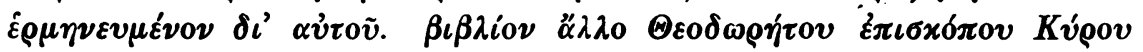

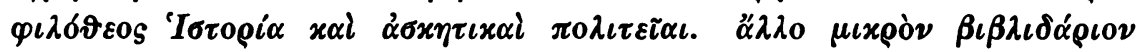

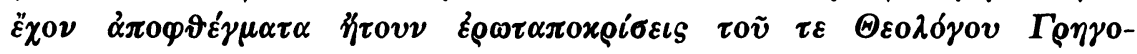

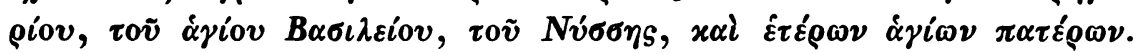

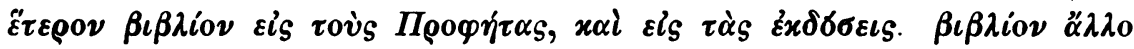

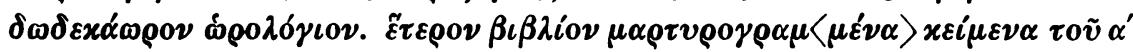

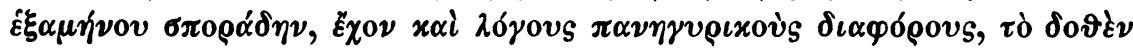

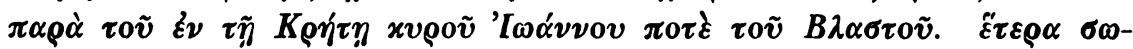

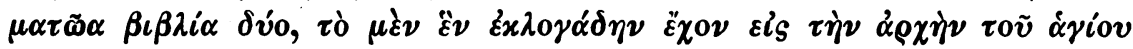

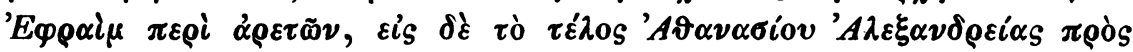

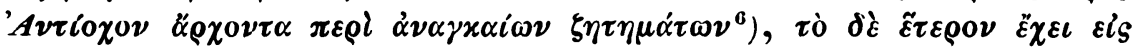

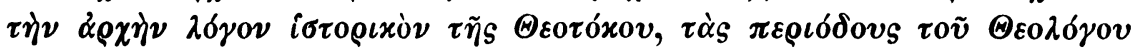

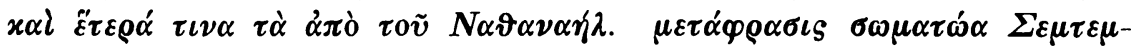

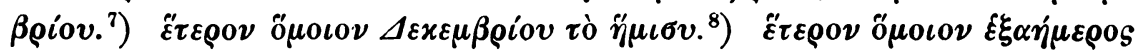

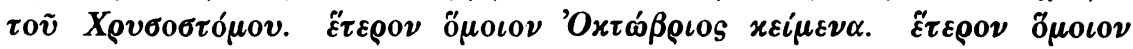

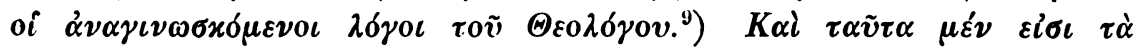

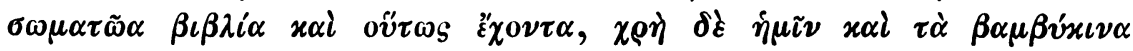
$\dot{\alpha} \nu \alpha \gamma \rho \alpha ́ \psi \alpha \alpha$.

1) Sur ce personnage, Fabricius, IX, 282.2 2) no 266 (?). lion, p. 40-41, et Christ, Gesch. d. griech. I.itt., $2^{\mathrm{e}}$ éd. 749-750.

3) Cf. Sakke4) no 111 . 5) Partie du no 263 (Sakkelion, p. 128). 6) Cf. Sakkelion, p. 7 (no 17) et p. 68 (no 112). 7) no 271 . 8) no 239. 9) no 45. Ces sept derniers numéros, depuis

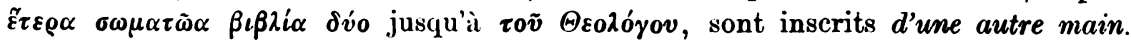




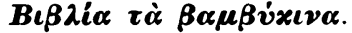

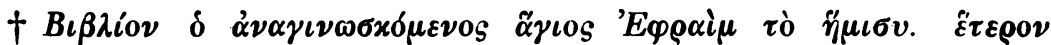

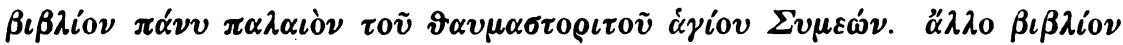

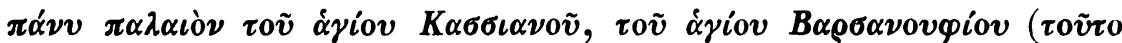

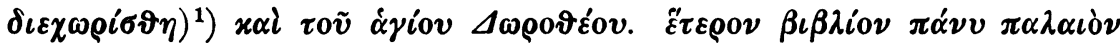

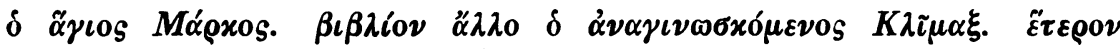

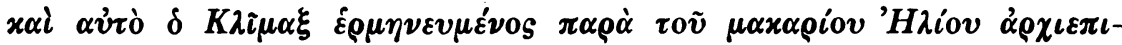

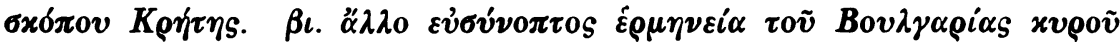

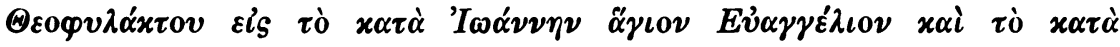

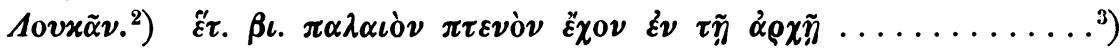

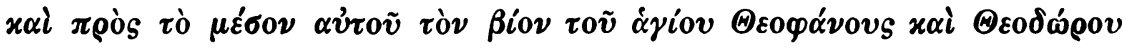

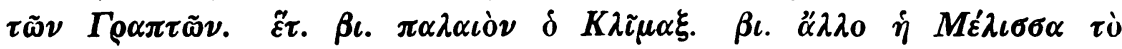

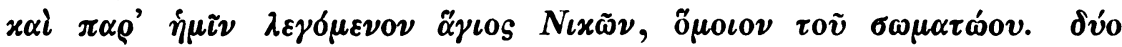

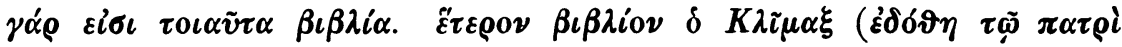

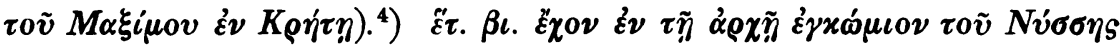

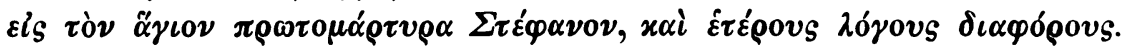

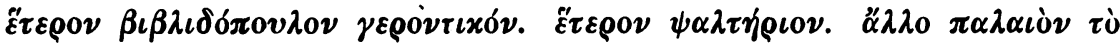

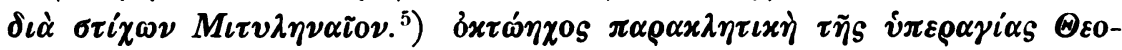

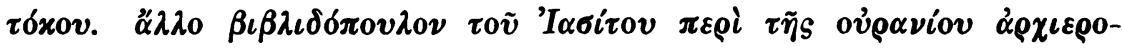

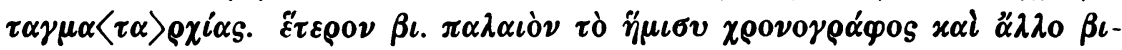

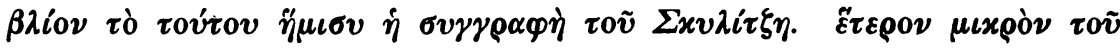

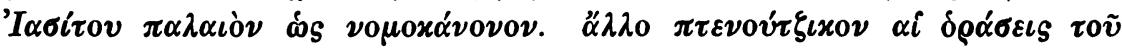

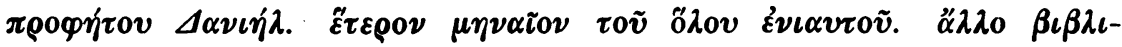

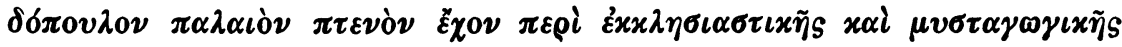

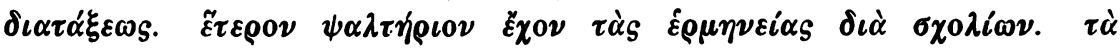

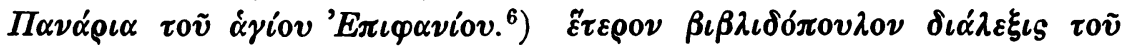

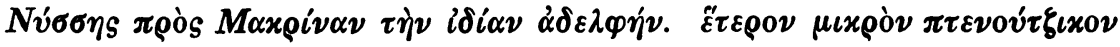

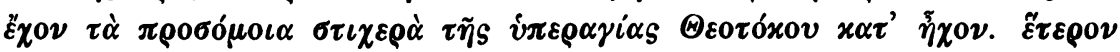

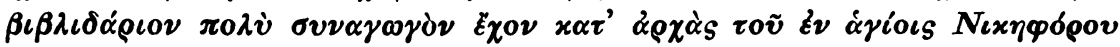

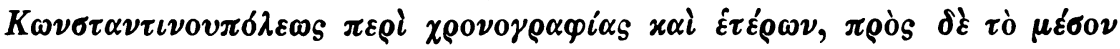

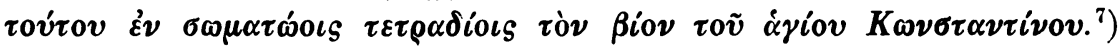

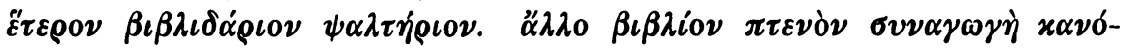

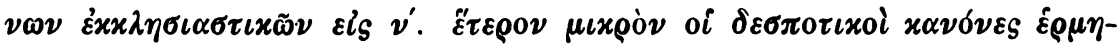

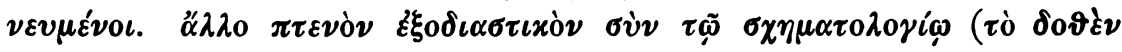

1) La phrase entre parenthèses est inscrite $\grave{a}$ la marge.

2) no 360 .

3) Blanc dans le ms.

4) La phrase entre parenthèses est écrite au dessus de la ligne.

5) Ce volume renfermait sans doute les œurres de Christophe de Mytilène.

(ff. sur cet écrivain, Krumbacher, Gesch. d. Byz. Iitt., p. 354.

6) Cf. Christ, Gesch. d. griech. Litt., $2^{\mathrm{e}}$ ed. p. $\mathbf{7 4 6 .}$

7) Cf. no 179. 


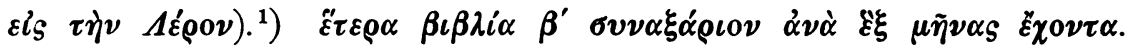

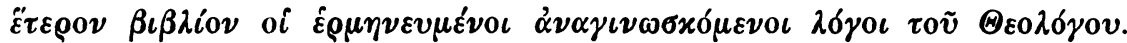

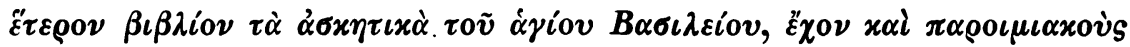

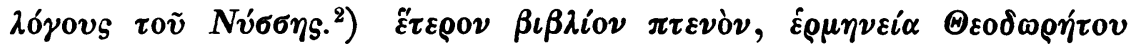

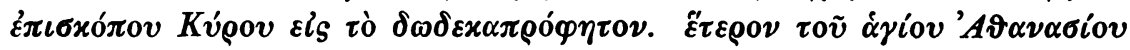

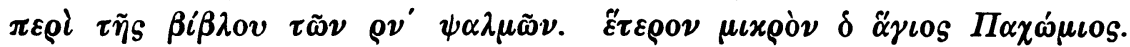

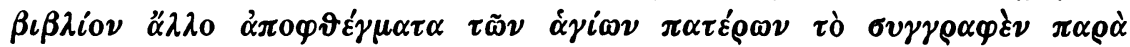

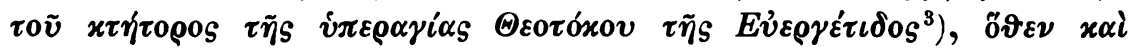

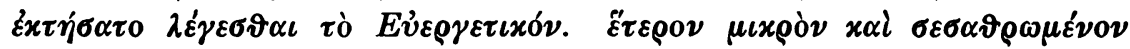

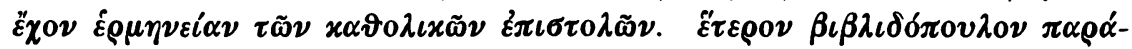

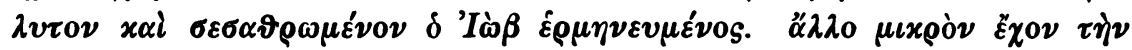

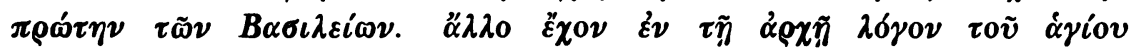

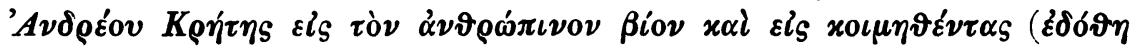

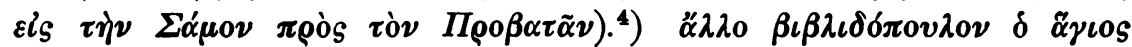

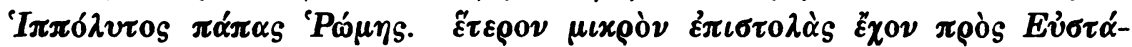

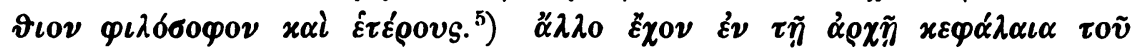

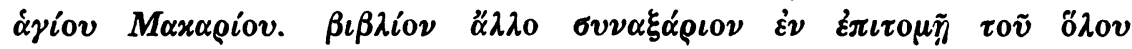

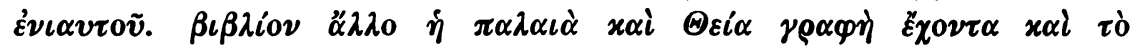

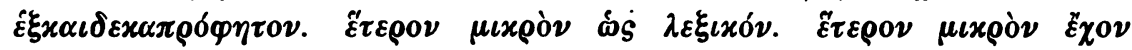

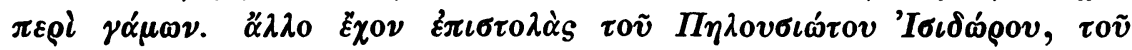

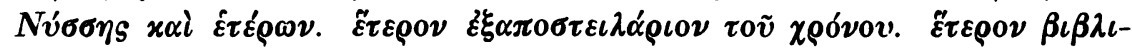

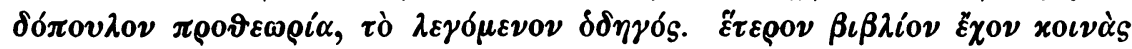

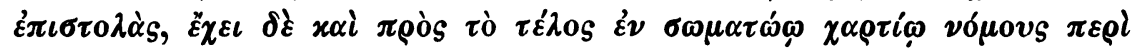

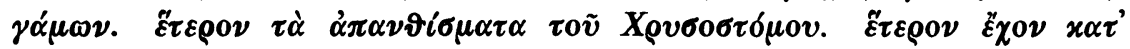

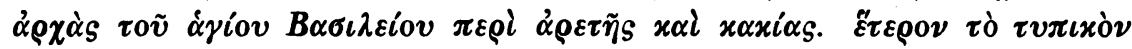
$\tau \tilde{\eta}_{S}$ Moṽ̃

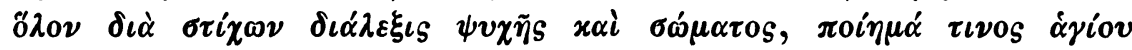

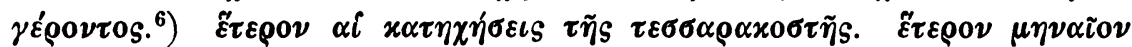

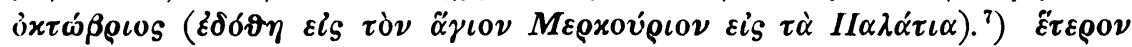

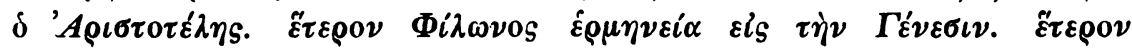

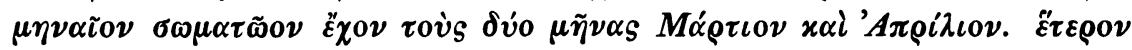

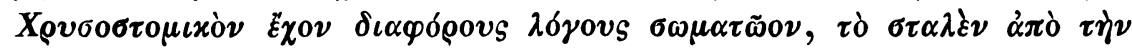

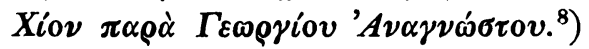

1) La phrase entre parenthèses est écrite au dessus de la ligne.

2) no 304 (?).

3) Cf. Sakkelion, p. 199 (no 441. 442).

4) La phrase entre parenthèses est écrite au dessus de la ligne.

5) no 326 (?).

6) Cf. Sathas, Bibl. gr. med. aevi, t. I, p. 273 et 292.

7) La phrase entre parenthèses est écrite au dessus de la. ligne.

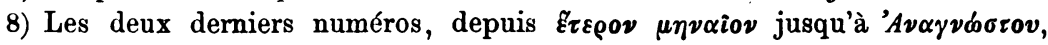
sont inscrits d'une autre main. 
$\mathrm{Au}$ verso du catalogue on lit les indications suivantes:

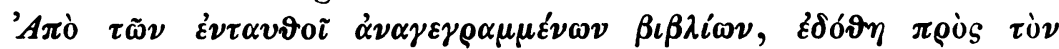

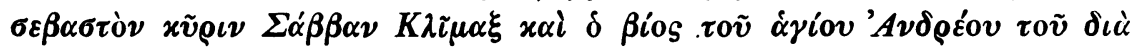
X

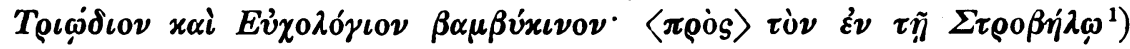

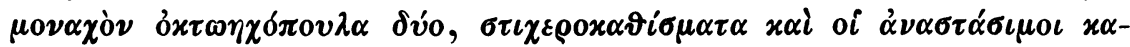

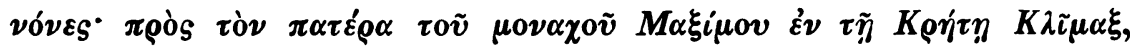

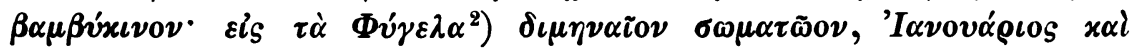

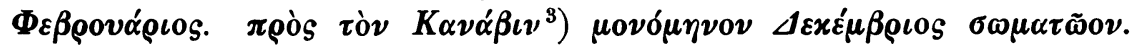

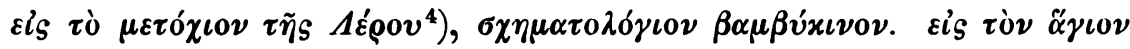

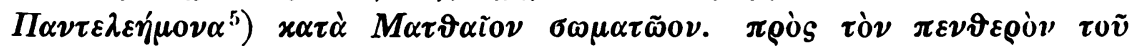

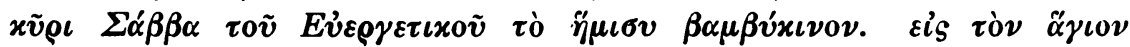

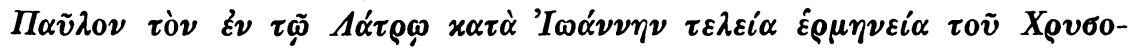

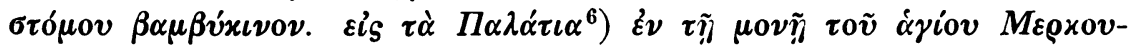

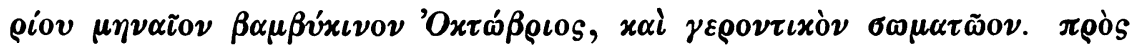

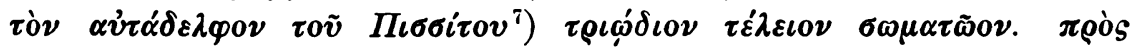

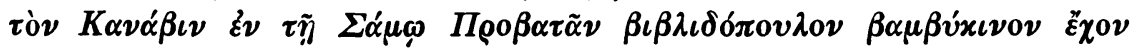

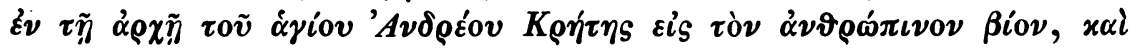

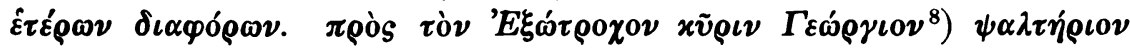

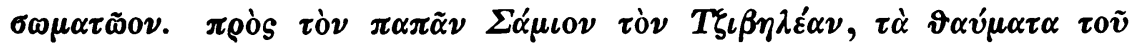

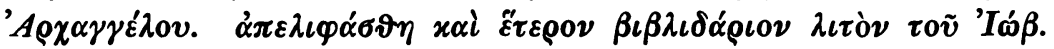

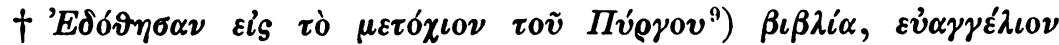

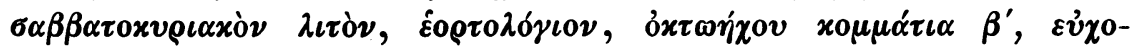

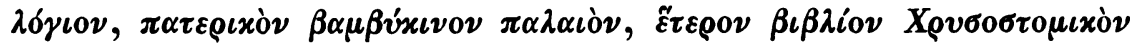

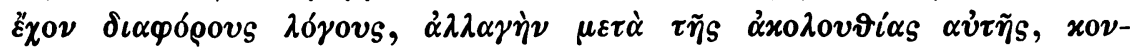

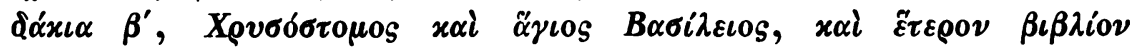

1) Sur Strobilos et les relations qui unissent ce couvent à Patmos, Acta, p. 62.

2) Phygela, petit port de la côte d'Anatolie, où Patmos possédait une métochie. Acta, p. 166. 174. Cf. p. 179. 182 et Const. Porphyrog., De Cerim., II 44. Cf. aussi Tomaschek, Zur hist. Topographie von Kleinasien im Mittelalter, (Sitzungsber. der Akad. d. Wissensch. zu Wien, Phil. hist. Kl. Jahrg. 1891) p. 34-39.

3) Sur ce nom propre, cf. Acta, p. 234.

4) Sur la métochie de Léros, Acta, p. 200.

5) La métochie de St. Pantéléimon se trouvait sur la côte d'Anatolie, près

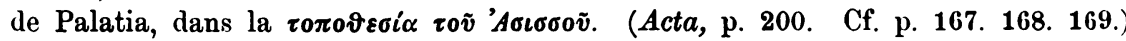

6) Palatia est bâti sur l'emplacement de l'antique Milet.

7) Sur la famille des Pissitès, domiciliée à Palatia, Acta, p. 153.

8) Sur cette famille, que l'on rencontre en Crète et à Palatia, Acta, p. 133.182.

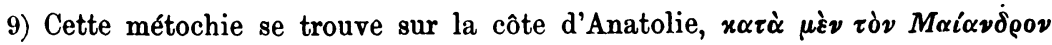

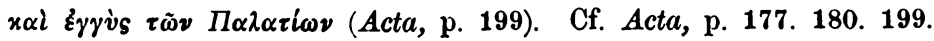




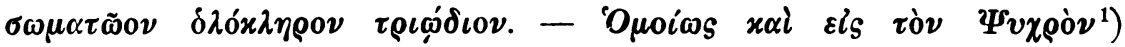

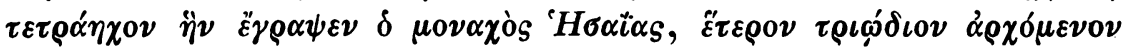

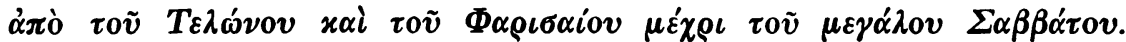

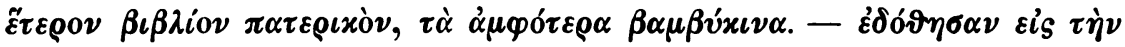

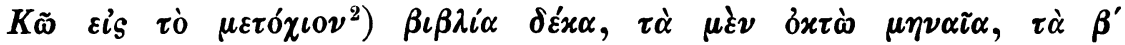

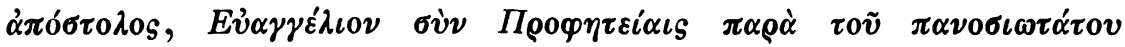

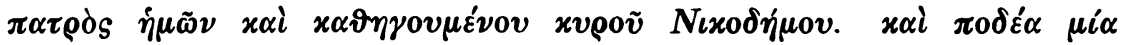

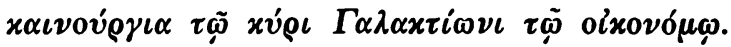

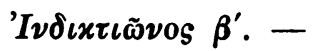

Nancy.

\section{Ch. Diehl.}

\section{Mosaïques byzantines de Nicée.}

M. Strzygowski a pris la peine d'ajouter quelques indications fort utiles à la description que j'avais donnée des mosaïques de Nicée. Les monogrammes de l'arc triomphal avaient en effet échappé à mon attention; j'avais noté toutefois ceux qui sont inscrits aux chapiteaux des pilastres; mais n'en pouvant donner une interprétation satisfaisante, j'avais jugé peu nécessaire de les publier. Depuis lors, j'ai eu occasion d'étudier à nouveau ces monogrammes, et sans pôuvoir présenter encore un déchiffrement certain du second, j'incline à proposer pour le premier une correction à la lecture de M. Strzygowski. Ce monogramme offre en effet une forme un peu différente du dessin qui en a été donné (Byz. Zeitschrift, p. 340); l'aspect en parait être celui-ci:

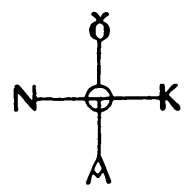

On remarquera que la partie centrale de ce monogramme offre fort nettement la lettre $T$ : c'est une première raison pour écarter la lecture

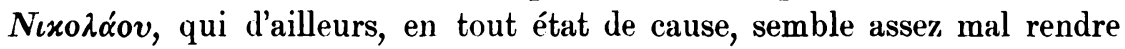
compte du monogramme. $N_{t}$ serait-il point possible de lire ici $\mathbf{N} \alpha v$ -

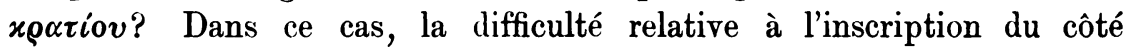

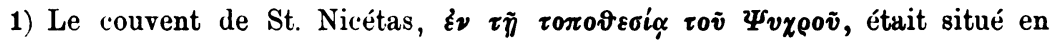
Crète. Il fut donné en 1196 au monastère de Patmos (Acta, p. 131).

2) Sur la métochie de Cos, dite de la Theotokos $\tau \tilde{\omega} \nu$ $\Sigma \pi 0 \nu \delta \tilde{\omega} \nu$, cf. Acta, p. 184. 193. 200 . 